AlllOz 5bl2?

NAT'L INST OF STANDARDS \& TECH R.I.C.

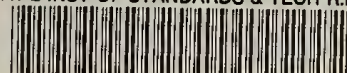

A11102561272

NBS

PUBLICATIONS

Collins, Bellinda Low/Visual assessment o
QC100.U56 NO.86-3409 1986 V19 C.1 NBS-P

\title{
Visual Assessment of Holograms
}

Belinda L. Collins

U.S. DEPARTMENT OF COMMERCE

National Bureau of Standards

Center for Building Technology

Building Physics Division

Gaithersburg, MD 20899

July 1986

\section{Sponsored by:}

n....... of Engraving and Printing

$-a C$ Aasury Dopartment

$100 \quad$ yton, DC

.1156

$86-3409$

1986 



\title{
VISUAL ASSESSMENT OF HOLOGRAMS
}

\author{
Belinda L. Collins
}

U.S. DEPARTMENT OF COMMERCE

National Bureau of Standards

Center for Building Technology

Building Physics Division

Gaithersburg, MD 20899

July 1986

Sponsored by:

Bureau of Engraving and Printing U.S. Treasury Department Washington, DC

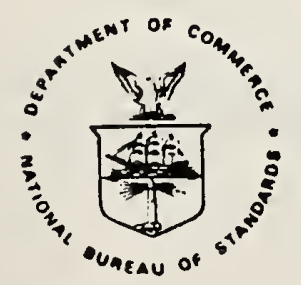

U.S. DEPARTMENT OF COMMERCE, Malcolm Baldrige, Secretary NATIONAL BUREAU OF STANDARDS, Ernest Ambler, Director 



\section{Abstract}

At the request of the Bureau of Engraving and Printing, NBS performed an assessment of the effectiveness of holograms intended for use as security devices on banknotes. Five holograms containing different portraits and counters were hotstamped on banknote currency of five different denominations. A total of 66 notes were studied. Fifty of these banknotes were subjected to one of five wear tests - chemical soak, laundering, one crumple, two crumple, and four crumple. Another six notes contained counterfeited holograms, while the final ten notes remained in the pristine condition. Thirty observers then participated in a visual performance experiment with the 66 banknotes in which they detected the image, counter, and seal in each hologram, matched the holographic image and counter to the portrait and counter on the note, rated the quality of each hologram, and indicated if it were genuine or counterfeit. The results indicated that wear adversely affected the performance of the holograms, with all wear conditions except chemical soak resulting in significantly poorer performance than the pristine condition, well below the criterion of 80 percent accuracy. Correlations with a physical measure of hologram quality, diffraction efficiency, were strongest for the rated quality measures, and were above 0.80 for image data. The data indicate strongly that the holograms studied could not pass the standard wear tests that conventional banknote currency regularly does.

Reywords :

Banknotes; counterfeit; currency; detection; hologram; identification; optically variable devices; wear 
This report is one of a series documenting the results of NBS research in support of Bureau of Engraving and Printing Contract No. V-0283-09, entitled "Noticeability of Features of Secure. Documents". The report summarizes research conducted from January 1986 to July 1986.

\section{ACKNOWLEDGEMENTS}

We wish to acknowledge with special thanks the interest, cooperation, and encouragement of the sponsor's Technical Project Officer, MS. Barbara A. Vaudreuil, Manager, Research and Development Division, Office of Research and Technical Services, as well as that of Mr. John Mercer, Manager, Product Assurance Division. 
Table of Contents

ABSTRACT ...........................................

FOREWORD ........................................

ACKNOWLEDGEMENTS ................................. iv

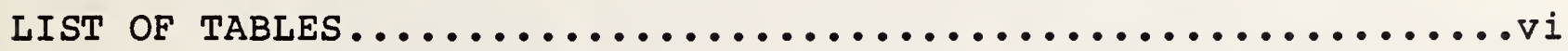

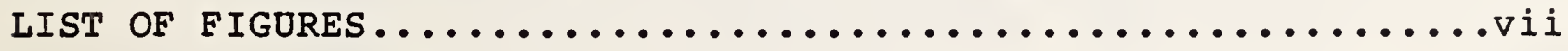

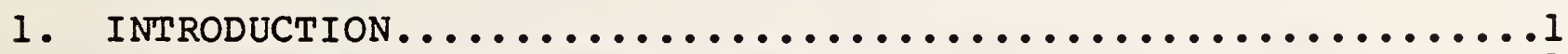

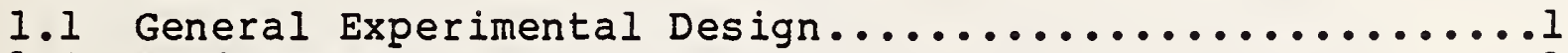

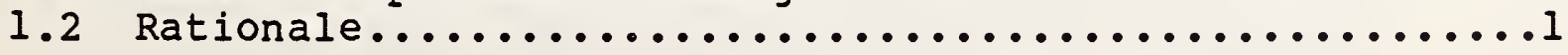

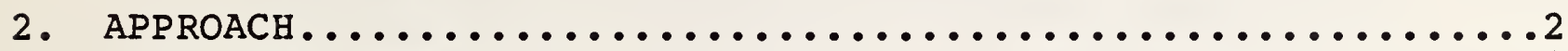

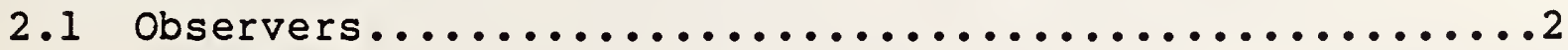

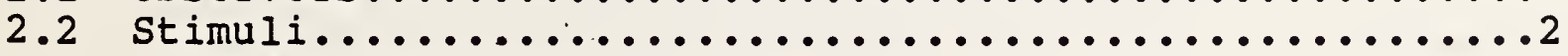

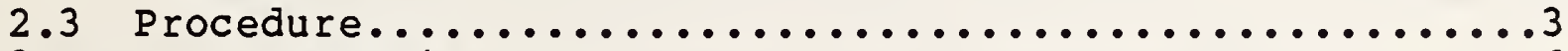

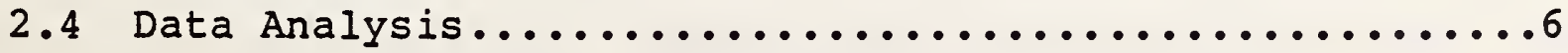

3. RESULTS .....................................7

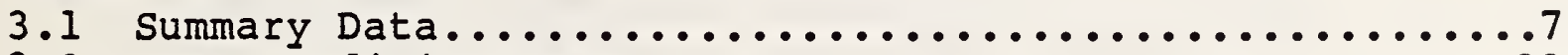

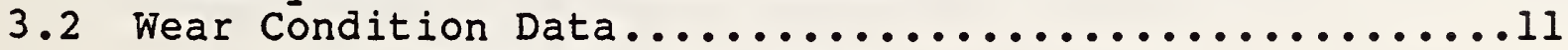

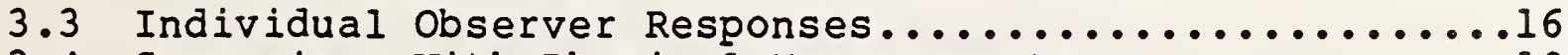

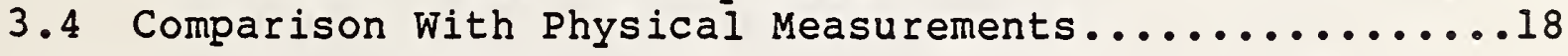

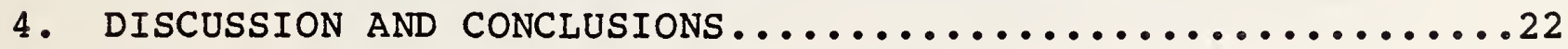

5. RECOMMENDATIONS ....................................24

6. REFERENCES .................................... 25

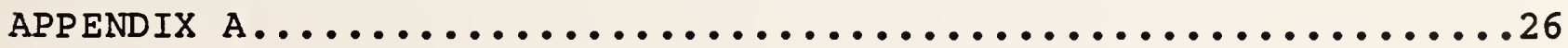




\section{LIST OF TABLES}

Page

Table 1. Identification of samples....................

Table 2. Instructions to observers....................

Table 3. Summary data of overall hologram performance.......8

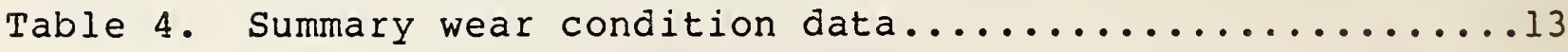

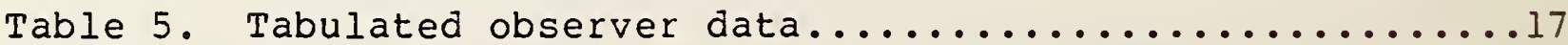

Table 6. Matrix of correlation coefficients between physical

and visual performance measures.................20

Appendix A

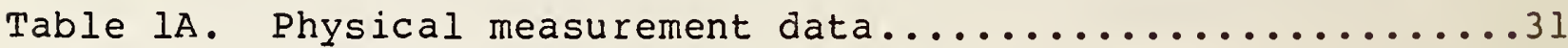

Table 2A. Comparison of physical measurement data with visual

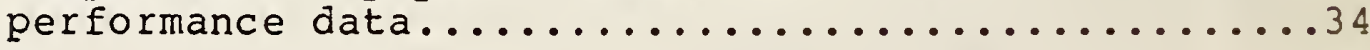


Figure 1a. Percentage of correct detection of the three holographic elements, image, denomination counter, and seal as a function of wear condition. Data for image detection are given first, followed by the

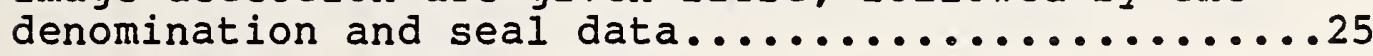

Figure 2a. Percentage of correct matches between hologram image and note portrait, and hologram denomination counter and note denomination counter for all notes as a function of wear condition. Data for the image match are given first followed by the data for the denomination match...........26

Figure $3 a$. Mean ratings of hologram quality as a function of wear condition. The first entry in a wear condition refers to matched notes; the second to mismatched notes ............................27

Figure 4a. Percentage of notes rated as genuine as a function of wear condition. The first entry in a wear condition refers to matched notes; the second to

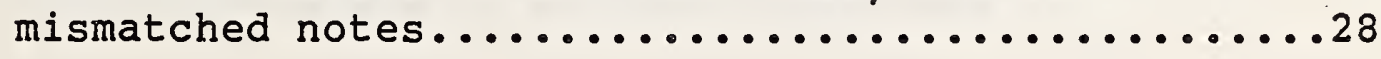



At the request of the Bureau of Engraving and Printing (BEP), the National Bureau of Standards (NBS) conducted a study at BEP to evaluate the visibility and general effectiveness of holograms intended for use on paper currency. The study was intended to assess the visibility and recognizability of proposed holograms for notes in five different denominations which had been subjected to standard wear tests. Results from a parallel study which provided physical measures of the optical characteristics of the holograms were also compared with the visual performance results from the present study.

\subsection{General Experimental Design}

Five different holograms were used in the evaluation. Each hologram contained three elements: an image, a denomination counter, and a Federal Reserve Seal. The hologram image and counter were designed to match the banknote portrait and counter for each denomination. The holograms were hotstamped on a series of banknotes, to the left of the portrait, replacing the current Federal Reserve Seal.

A total of 66 notes were used in the study. Fifty of these were subjected to one of five wear tests - chemical soak $130 \mathrm{~min}$ in ethanol), laundering, one crumple, two crumple, and four crumple, while another ten notes remained in the pristine condition. Six additional notes contained counterfeited holograms.

The wear tests are standard ones used by BEP to test currency fitness (See BEP Test Method RT-86-01,02, and 03). Since banknotes which pass these wear tests are considered fit for circulation, it was of interest to determine if the notes with holograms would also be "fit." For holograms, a reasonable criterion for "fitness" appears to be that the three elements can be detected, and that the holographic image and denomination counter can be matched with the portrait and denomination counter on the note by at least $80 z$ of the observers, for notes subjected to any wear condition.

\subsection{Rationale}

The present study was designed to be an evaluation of visual performance with holograms intended for eventual use on banknotes. In addition, it was designed so that visual performance data could be compared with physical measurement data for the same set of banknotes. The goal of this latter comparison was to predict the visual effectiveness of holograms for a given wear condition as a function of optical measurements. The study used some of the methodologies developed by Collins (1985) in an earlier assessment of the visual effectiveness of Optically Variable Devices (OVD's). 


\section{Approach}

\subsection{Observers}

A total of 30 observers participated. This number was large enough to allow meaningful statistical comparisons, yet small enough to allow rapid data acquisition and analysis. The observers were employees of the Bureau of Engraving and Printing, and included 15 males and 15 females in a variety of job classifications. No observer had worked with the materials prior to the experiment.

\subsection{Stimuli}

The stimuli included 5 conventionally produced holograms and 3 "counterfeited" holograms. Each hologram was $16 \mathrm{~mm}$ in diameter. The conventionally produced holograms included an image, seal and denomination counter for each denomination, as follows:

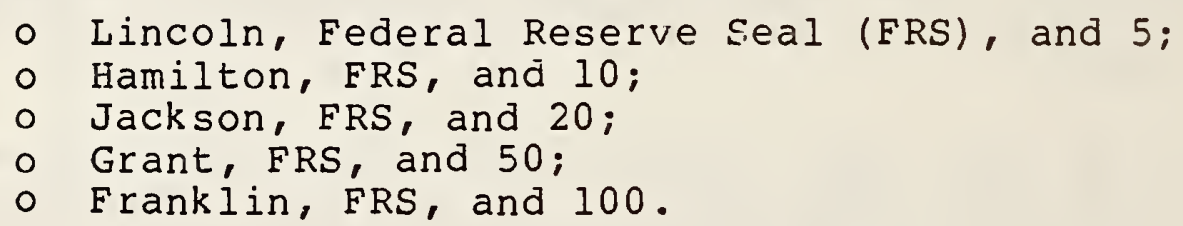

The counterfeited hologram, made by a non-commercial process, included the following conbinations:

Lincoln, FRS, $5 ;$
O Hamilton, FRS, $10 ;$
O Franklin, FRS, 100.

The counterfeit holograms were golden rather than silver in color, but were about the same size as the "genuine" hologram.

The intent of using holograms as a cue for genuineness is that the user should be able to match the elements (image and denomination) to the same elements on the note jtself. Thus, a $\$ 5$ note would have the Lincoln hologram with a 5 and a seal. An important goal of the present experiment was to determine if observers could match the hologram to the note. To control for random guessing, half the notes were mismatched; that is, the hologram elements did not match those of the banknote. The mismatch was achieved by hotstamping the holograms on the wrong denomination. This meant that the image and the counter agreed within the hologram but not with the engraving on the note. Thus, the hologram containing Franklin and 100, for example, was hotstamped onto $\$ 5, \$ 10, \$ 20$ and $\$ 50$ banknotes. As a result, there was no situation in which the images matched but the counters did not match (or vice versa). 
A total of 66 notes was used, of which 6 contained counterfeited holograms. Half the notes (33) were mismatched, including the counterfeits. Ten notes, five matched and five mismatched, were used for each wear condition - laundered, chemical soak, one crumple, two crumple, and four crumple. Ten notes remained in the pristine condition. Only one example of a mismatch was included for each denomination in each wear condition to reduce the sample size to a manageable number. Care was taken, however, to include mismatched notes with all five holograms in each wear condition (but not all twenty-five possible mismatches). Table $I$ identifies the notes used in the study.

\subsection{Procedure}

Each observer individually viewed all 66 notes. The observers were seated at a table covered with a neutral gray surface. Two fluorescent luminaires were above the table, one to either side of the observers. An illuminance of about $70 \mathrm{fc}$ ( 700 lux) was maintained on the desk surface. Observers were given the instructions (see Table 2) to read. They were then given two pristine matching notes, $a$ \$10 and a $\$ 50$, to examine, and asked to report what they saw. They were reminded to look for the three elements, and to match the image and counter. In addition, they were told that the two notes were excellent examples of genuine good condition notes. Observers were not given specific criteria by which to judge genuineness but instead were allowed to develop their own criteria - which unfortunately resulted in some inconsistency.

Once the experiment started, an observer picked up each note, tilted it from side to side and back and forth, gave his/her responses, and handed the note back to the experimenter.

Seven different responses were obtained. The first three concerned the detectability of the three holographic elements: the image, denomination counter, and seal. The fourth and fifth involved a match between the hologram image and note portrait, and a match between the hologram counter and note counter. The sixth response was a rating of hologram quality using a sevenpoint scale, while the seventh was a judgement of hologram genuineness.

Observers were given sufficient time to view each note and respond completely. The experiment typically took 40 to 60 minutes to complete. While this was obviously much longer than any normal currency transaction, it was intended to elicit as much information as possible about each note.

The notes were randomized prior to each viewing session with one constraint; namely, observers always began pristine matching $\$ 5$ note. This provided an with note \#1, a information about good quality notes. 
Table 1. Identification of Samples

\begin{tabular}{|c|c|c|c|c|c|}
\hline \multicolumn{3}{|c|}{ Matched } & \multicolumn{3}{|c|}{ Mismatched } \\
\hline $\begin{array}{l}\text { Wear } \\
\text { Condition }\end{array}$ & Denom & ID Number & Denom & ID & Numbe \\
\hline Pristine & $\begin{array}{r}5 \\
10 \\
20 \\
50 \\
100\end{array}$ & $\begin{array}{l}1 \\
2 \\
3 \\
4 \\
5\end{array}$ & $\begin{array}{rl}5 & h \\
10 & h \\
20 & h \\
50 & h \\
100 & h\end{array}$ & $\begin{array}{l}w / 100^{1} \\
w / 20 \\
w / 50 \\
w / 5 \\
w / 10\end{array}$ & $\begin{array}{l}34 \\
35 \\
36 \\
37 \\
38\end{array}$ \\
\hline Laundered & $\begin{array}{r}5 \\
10 \\
20 \\
50 \\
100\end{array}$ & $\begin{array}{r}6 \\
7 \\
8 \\
9 \\
1.0\end{array}$ & $\begin{array}{rl}5 & h \\
10 & h \\
20 & h \\
50 & h \\
100 & h\end{array}$ & $\begin{array}{l}w / 50 \\
w / 5 \\
w / 10 \\
w / 100 \\
w / 20\end{array}$ & $\begin{array}{l}39 \\
40 \\
41 \\
42 \\
43\end{array}$ \\
\hline Chem Soak & $\begin{array}{r}5 \\
10 \\
20 \\
50 \\
100\end{array}$ & $\begin{array}{l}11 \\
12 \\
13 \\
14 \\
15\end{array}$ & $\begin{array}{r}5 \\
10 \\
20 \\
50 \\
100\end{array}$ & $\begin{array}{l}w / 10 \\
w / 20 \\
w / 5 \\
w / 100 \\
w / 50\end{array}$ & $\begin{array}{l}44 \\
45 \\
46 \\
47 \\
48\end{array}$ \\
\hline One Crumple & $\begin{array}{r}5 \\
10 \\
20 \\
50 \\
100\end{array}$ & $\begin{array}{l}16 \\
17 \\
18 \\
19 \\
20\end{array}$ & $\begin{array}{r}5 \\
10 \\
20 \\
50 \\
100\end{array}$ & $\begin{array}{l}w / 50 \\
w / 5 \\
w / 100 \\
w / 10 \\
w / 20\end{array}$ & $\begin{array}{l}49 \\
50 \\
51 \\
52 \\
53\end{array}$ \\
\hline Two Crumpie & $\begin{array}{r}5 \\
10 \\
20 \\
50 \\
100\end{array}$ & $\begin{array}{l}21 \\
22 \\
23 \\
24 \\
25\end{array}$ & $\begin{array}{r}5 \\
10 \\
20 \\
50 \\
100\end{array}$ & $\begin{array}{l}w / 100 \\
w / 5 \\
w / 50 \\
w / 20 \\
w / 10\end{array}$ & $\begin{array}{l}54 \\
55 \\
56 \\
57 \\
58\end{array}$ \\
\hline Four Crumple & $\begin{array}{r}5 \\
10 \\
20 \\
50 \\
100\end{array}$ & $\begin{array}{l}26 \\
27 \\
28 \\
29 \\
30\end{array}$ & $\begin{array}{r}5 \\
10 \\
20 \\
50 \\
100\end{array}$ & $\begin{array}{l}w / 20 \\
w / 5 \\
w / 10 \\
w / 5 \\
w / 50\end{array}$ & $\begin{array}{l}59 \\
60 \\
61 \\
62 \\
63\end{array}$ \\
\hline Counterfeit & $\begin{array}{r}5 \\
10 \\
100\end{array}$ & $\begin{array}{l}31 \\
32 \\
33\end{array}$ & $\begin{array}{r}5 \\
10 \\
20\end{array}$ & $\begin{array}{l}w / 10 \\
w / 5 \\
w / 100\end{array}$ & $\begin{array}{l}64 \\
65 \\
66\end{array}$ \\
\hline
\end{tabular}

1 The first number refers to the note denomination; the second to the hologram denomination. 
The U.S. Treasury is considering using holograms on banknotes. The hologram is used to reinforce elements of the note. It contains an image of the same person shown in the note portrait, a counter for the denomination, and the Federal Reserve seal. To assess the effectiveness of holograms, the Treasury has printed up a set of banknotes with holograms on different denominations in different wear conditions for use in the present experiment. There are five denominations: $\$ 5, \$ 10, \$ 20, \$ 50$, an $\$ 100$. Each denomination has a holographic image corresponding to the portrait. Thus, the $\$ 5$ note has both a portrait of Abraham Lincoln and a holographic image of Lincoln. In addition, each hologram has a counter (in this case, 5), and a Federal Reserve Seal as well as the image. Thus, there are three elements to each hologram - image, counter, and seal. Here are some examples of banknotes in good condition with the proper holograms attached.

In this experiment, you will see a series of banknotes with holograms located to the left of the portrait. These banknotes are in different wear conditions, making it harder to see the elements in the hologram. In addition, the images and counters in some of the holograms do not match the note's portrait and counter. These holograms are considered to be mismatched. Some are even counterfeited.

We are interested in determining if you can see the elements in the holograms on the banknotes, and can match them with the portrait and counter printed on the note. To do this, please pick up the banknote and look at it briefly. To see the elements in the hologram, you will need to tilt the note in different directions - back and forth, and up and down. You need to look only at the front of the note, since there are no holograms on the rear.

After you have examined the note, please give me several pieces of information. First please tell me if you saw anything in the hologram. You should see an image, a counter, and a Federal Reserve seal. Secondly, please tell me if the hologram matches the note; and if it does match, what matches. The image should match the portrait, and the counter should match the four counters at the edges of the note. Third, please rate the quality of the hologram using a scale of 1 to 7. In this scale a 1 would mean that the hologram was clear and contained all three elements (image, counter and seal), while a 7 would mean that no elements or pieces of elements were visible. Finally, please indicate if the hologram is genuine or counterfeited. When you have finished, please hand the note to me.

There will be a total of 66 notes in all. The experiment should take about 45 minutes. Do you have any questions? 


\subsection{Data anaiysjs procedure}

Following completion of data collection, the data were entered into a spreadsheet program. Responses for each of the seven data types (image; denomination anci seal detection; image and denomination counter match; counter; rated quality; and judgements of genuineness) were then tabulated for each banknote and observer.

The detection data were tabulated in two separate analyses. The first was the detection of an element, while the second was the order in which each element was mentioned. This latter arilysis was intended to give some indication of which elements were seen (or, at least mentioned) first. The matching data were tabulated in terms of correct resicnse, no response, or error (incorrect matching response). A distribution of quality ratings was also tabulated for each note and wear condition. Finally, the frequency of "genuine" responses was tabulated for each note.

Means, standard deviations and mean ratings of hologram quality were then calculated for the different responses. A separate statistical program was used to calculate statistical comparisons such as chi square and correlation coefficients. 
3. Results

\subsection{Summary Data}

Table 3 presents summary frequency and percentage data for hologram performance in four categories - detection accuracy (table $3 a$ ), matching accuracy (table $3 b$ ), rated quality (table $3 c)$, and judgements of genuineness (table $3 d$ ). Results are given for the 33 matching notes, the 33 mismatched notes, and the combined 66 notes. Appendix A presents four figures summarizing the data for hologram performance.

The first set of entries (table $3 a$ ) presents data for the detectability of the image, denomination, and seal. As noted earlier, two types of data were tabulated: detectability of an element (Yes and No entries in table 3); and order of detection. The latter category refers to the order in which each element was mentioned by the observer and is represented by $1,2,3$ or see in table 3. (The see category represents cases in which observers indicated seeing everything, without mentioning the order in which they saw specific elements.) The Yes category then combines the $1,2,3$, and See responses, while the No category represents only those times when observers did not see an element. The number of No's thus provides information on the failure to detect a particular element.

Inspection of the Yes and No data given in table $3 a$ indicates that the denomination counter in the hologram was detected more frequently than the seal or the image (69 percent vs 58 percent). These data also demonstrate that observers failed to detect each holographic element more than 30 percent of the time.

The data recorded for order of detection indicate clearly that the denomination was mentioned first, the image second, and the seal third. Thus, as can be seen from the "combined" columns, the denomination was mentioned first by 39 percent of the observers and second by 23 percent, while the image was mentioned first by 23 percent of the observers, and second by 26 percent. The seal was mentioned first by only 14 percent, but third by 29 percent. The pattern of responses for detection order was similar for both matched and mismatched bills.

A chi square analysis was performed to assess the differences in the distribution of detection responses for order, excluding the no response category (Natrella, 1966). This analysis revealed that the detection order was significantly different ( $p<.001$ ) for the image vs denomination, for image vs seal, and for denomination vs seal comparisons. A second analysis revealed no difference in overall detection accuracy (number of Yes responses vs No responses) between matched and mismatched notes for either image or denomination data. 
Table 3. Summary Data of Overall. Hologram Performance

Table 3a. Order of Detection

Image

Matched

Freq Percent

Detection

Order

$\begin{array}{rrr}1 & 245 & 24.75 \\ 2 & 233 & 23.54 \\ 3 & 79 & 7.98 \\ \text { SEE } & 32 & 3.23\end{array}$

TOTAL

YES

$589 \quad 59.49$

40140.50
Mismatched

Freq Percent
Combined

Freq Percent

$\begin{array}{rrr}1 & 203 & 20.51 \\ 2 & 285 & 28.79 \\ 3 & 75 & 7.58 \\ \mathrm{SEE} & 4 & 0.40\end{array}$

$\begin{array}{rrr}1 & 448 & 22.63 \\ 2 & 518 & 26.16 \\ 3 & 154 & 7.78 \\ \mathrm{SEE} & 36 & 1.82\end{array}$

YES

NO
$1156 \quad 58.38$

$824 \quad 41.62$

Denomination

Matched

Freq Percent

Detection

Order

$\begin{array}{rrr}1 & 340 & 34.34 \\ 2 & 242 & 24.44 \\ 3 & 56 & 5.66 \\ \text { SEE } & 33 & 3.33\end{array}$

Mismatched

Freq Percent

$\begin{array}{rrr}1 & 431 & 43.54 \\ 2 & 225 & 22.73 \\ 3 & 35 & 3.54 \\ \mathrm{SEE} & 5 & 0.51\end{array}$

$\begin{array}{rrr}1 & 771 & 38.94 \\ 2 & 467 & 23.59 \\ 3 & 91 & 4.60 \\ \text { SEE } & 38 & 1.92\end{array}$

TOTAL

YES
NO

$\begin{array}{lll}671 & 67.77\end{array}$

$319 \quad 32.55$

YES

$\begin{array}{rr}696 & 70.303\end{array}$

YES

1367

69.04

NO

Seal

Matched

Freq Percent

Mismatched

Freq Percent

Combined

Freq Percent

Detection

order

$\begin{array}{rrr}1 & 153 & 15.45 \\ 2 & 129 & 13.03 \\ 3 & 257 & 25.96 \\ \text { SEE } & 37 & 3.74\end{array}$

$\begin{array}{rrr}1 & 129 & 13.03 \\ 2 & 137 & 13.84 \\ 3 & 311 & 31.41 \\ \text { SEE } & 8 & 0.81\end{array}$

1
2
3
SEE

282

266

14.24

568

13.43

28.69

$\begin{array}{ll}45 & 2.27\end{array}$

TOTAL

YES

NO $\begin{array}{rrr}585 & 59.090 & \text { YES } \\ 405 & 41.33 & \text { NO }\end{array}$
$1161 \quad 58.64$

81941.36 
Table 3b. Portrait and Denomination Matching Image Data

Matched

Freq Percent

None

Corr.

Error
$481 \quad 48.59$

$64 \quad 6.46$
$445 \quad 44.95$
Mismatched

Freq Percent

None $\quad 452 \quad 45.66$

Corr. $524 \quad 52.93$

Error $\quad 14 \quad 1.41$
Combined

Freq Percent

None $\quad 897 \quad 45.30$

Corr. $1005 \quad 50.76$

Error $78 \quad 3.94$

Denomination Data

Matched

Freq Percent
Mismatched

Freq Percent
Combined

Freq Percent

None $\quad 315 \quad 31.82$

Corr. $667 \quad 67.37$

Error

80.81

None $\quad 665 \quad 33.59$

Corr. $1286 \quad 64.95$

Error $29 \quad 1.46$

Combined Image and Denomination Data

Total $85 \quad 8.59$
Errors -
Matched
Notes

$\begin{array}{lllll}\text { Total } 22 & 2.22 & \text { Total } & 107 & 5.40 \\ \text { Errors - } & & \text { Errors } & & \\ \text { Mismatched } & & & \\ \text { Notes } & & & \end{array}$

Table 3c. Judgements of Rated Quality

Rating Frequency

\begin{tabular}{|c|c|c|c|c|c|c|c|c|}
\hline & \multicolumn{2}{|c|}{ Matched } & \multicolumn{3}{|c|}{ Mismatched } & \multicolumn{3}{|c|}{ Combined } \\
\hline Rate. & Freq & Percent & Rate. & Freq & Percent & Rate. & Freq & ercent \\
\hline $\begin{array}{l}0 \\
1 \\
2 \\
3 \\
4 \\
5 \\
6 \\
7\end{array}$ & $\begin{array}{r}0 \\
138 \\
62 \\
42 \\
60 \\
133 \\
206 \\
349\end{array}$ & $\begin{array}{r}0.00 \\
13.94 \\
6.26 \\
4.24 \\
6.06 \\
13.43 \\
20.81 \\
35.25\end{array}$ & $\begin{array}{l}0 \\
1 \\
2 \\
3 \\
4 \\
5 \\
6 \\
7\end{array}$ & $\begin{array}{r}0 \\
86 \\
80 \\
43 \\
45 \\
125 \\
209 \\
402\end{array}$ & $\begin{array}{r}0.00 \\
8.69 \\
8.08 \\
4.34 \\
4.55 \\
12.63 \\
21.11 \\
40.61\end{array}$ & $\begin{array}{l}0 \\
1 \\
2 \\
3 \\
4 \\
5 \\
6 \\
7\end{array}$ & $\begin{array}{r}0 \\
224 \\
142 \\
85 \\
105 \\
258 \\
415 \\
751\end{array}$ & $\begin{array}{r}0.00 \\
11.31 \\
7.17 \\
4.29 \\
5.30 \\
13.03 \\
20.96 \\
37.93\end{array}$ \\
\hline Mean & 5.0 & & Mean & 5.30 & & Mean & 5.16 & \\
\hline
\end{tabular}

Table 3d. Judgements of Genuineness

Frequency

\begin{tabular}{lrlllllll} 
& \multicolumn{3}{c}{ Matched } & & \multicolumn{3}{c}{ Mismatched } & \multicolumn{3}{c}{ Combined } \\
Freq & Percent & & Freq & \multicolumn{2}{c}{ Freq } & Percent \\
None & 12 & 1.21 & None & 9 & 0.91 & None & 21 & 1.06 \\
Gen. & 508 & 51.31 & Gen. & 291 & 29.39 & Gen. & 799 & 40.35 \\
Count & 470 & 47.47 & Count & 690 & 69.70 & Count 1160 & 58.59
\end{tabular}


The next entries in table 3, Portrait and Denomination Matching (table 3b), present data on the observers' ability to match the holographic image and counter to the note portrait and counter. Here, the data are presented in terms of no response (none), correct response (indicating correctly that a match or mismatch existed) and error (incorrect match). As with the detection data, more people gave no response to the image (45 percent) than to the counter ( 34 percent).

In addition, observers made the largest number of errors (incorrect match/mismatch) for the matched images, with this type of error occurring 64 times. Interestingly, thirty of these mismatch errors occurred with $\$ 100$ notes, with only 5-7 errors occurring for each of the other denominations. While this increase in errors may have occurred because observers were unfamiliar with $\$ 100$ notes, this seems unlikely since the mismatch errors occurred primarily for the case in which the hologram and portrait images matched. Unfamiliarity with $\$ 100$ notes should have increased the error rate for the mismatched $\$ 100$ notes as well. It seems more likely that the Franklin hologram was not as good a representation of the Franklin portrait as it should have been, and that observers actually had difficulty in matching the two.

The chi square analysis was used to compare the differences in the frequency of correct response between matched and mismatched notes. This comparison was significant for both the image and the denomination match data ( $p<.001)$. As noted earlier, observers made more matching errors, but not more detection errors, with the matched notes.

The third entry in table 3 (table $3 c$ ) presents data on the ratings of hologram quality. Observers rated the quality of each hologram on a scale of 1 to 7 , where 1 meant high quality and 7 meant poor quality. The holograms generally received ratings of 5 or above, (with a mean rating of 5.16) indicating that observers considered them to be poor quality. Holograms on matched notes received more ratings of 1 ( 13.9 vs 8.7 percent) but fewer ratings of 7 ( 35.2 vs 40.6 percent), thus suggesting that observers considered the matched notes to be of higher quality.

The fourth entry in table 3 (table $3 d$ ) presents the judgements of hologram genuineness. Although only 9 percent of the notes (a total of six) actually contained counterfeited holograms, observers considered that 59 percent of the notes were counterfeit. While they clearly considered mismatched bills to be counterfeit ( 70 vs 30 percent), they also considered 48 percent of the matched bills to be counterfeit. There was some tendency for observers to report that notes were counterfeit because of obvious wear in either the hologram or the paper. A few observers also mentioned the gold color and greater thickness 
of the true counterfeits with some asking if these were merely a different type of experimental hologram. While the experiment was not really successful in identifying actual counterfeit holograms, it did indicate that the observers had real reservations about both the quality and genuineness of the holograms (particularly after subjection to the different wear tests). It also indicated that observers correctly used a mismatch between the holographic image and portrait elements as an indicator of counterfeitedness.

\subsection{Wear Condition Data}

Table 4 presents summary percentage data (from the thirty observers) for each note in each condition - pristine, laundered, chemical soak, one crumple, two crumple, four crumple, and counterfeit. In this table, each note is identified by an arbitrary note number and denomination. Wear conditions are grouped together. The first five entries are for matched notes while the second five are for mismatched notes. Means and standard deviations are presented for each wear condition.

The first entries in table 4 present the percentage of correct detections of the image, denomination, and seal for each note. The correct detection category was obtained by combining the 1 , 2,3 and see detection responses. The next entries present the data for correct matches for both image and denomination. The percentage of genuine judgements for each note is given next, followed by the mean rating of hologram quality.

Examination of Table 4 reveals nearly perfect identification and match performance for the pristine condition with low standard deviations. The mean of the mean rating data is also lowindicating these holograms were generally seen as good quality. Although the number of pristine notes termed "genuine" is the highest for any wear condition, the standard deviation is also high - due to the observers' tendency to consider mismatched notes counterfeit. Performance was generally similar for the chemically soaked notes.

The other four wear conditions, laundering and crumpling (one, two, and four times), seriously degraded the observers' ability to detect and match the hologram elements. For these wear conditions, the percentage of matching the hologram image correctly ranged from 0 to 25 percent, while the accuracy of matching the counter correctly ranged from 9 to 33 percent. In fact, for the four crumple condition, no observer correctly matched any image. Holograms in these wear conditions also received high mean ratings (above 6.0) - indicating poor quality. Data for these four wear conditions indicate that wear impaired the effectiveness of the holograms, with mean percentages of accurately detecting and matching elements below 75 percent. 
Comparison of the performance for the "counterfeit" notes (given in the last entry in table 4) with that for notes in the pristine and chemically soaked conditions reveals that the frequency of correct detection was much lower for the seal than for either the image or the denomination data (4l percent vs 88 percent). This difference suggests that the observers had serious problems with some of the counterfeited hologram seals. Although the match data for the counterfeit notes are similar to the data for the pristine and chemically soaked notes, the counterfeit notes received a higher mean rating, indicating that observers considered them to be of poorer quality. In addition, they were termed genuine Iess frequently than notes in any other wear condition. In fact, the mismatched counterfeits were considered genuine by only 13-17 percent of the 30 observers. Clearly, observers considered these six holograms to be both poor quality and counterfeit.

The chi square statistic was used to compare differences in the distribution of responses as a function of wear condition. Data for the pristine condition were compared with those for each wear condition (chemical soak, laundered, one crumple, two crumple, and four crumple, as well as the counterfeits). The comparisons between each wear condition were made for the following data types - image detection, image match, denomination detection, denomination match, seal detection, and judgements of genuineness. All comparisons were significant $(p<.05)$ with two exceptions. In no case was the comparison of pristine with chemical soak significant. In addition, comparison of the data for the counterfeit condition with those for the pristine condition was not significant for either image or denomination detection.

The data were also compared with the 80 percent acceptance criterion suggested by Collins (1985). Inspection of table 4 reveals that the mean percentages for the detection and matching data failed to meet this criterion for the laundered, one crumple, two crumple and four crumple conditions. These comparisons reinforce the contention that wear adversely affects the observer's ability to use holograms effectively. Only the chemical soak did not degrade the hologram - and this because a mild chemical soak (30-min in ethanol) was included in the testing program. Other chemical soaks normally included in the BEP wear tests had destroyed the hologram so effectively that any visual performance assessment appeared meaningless. 
Pristine

\section{Correct Detection \\ Image Denom Seal}

NOTE DN Percent Percent Percent

$\mathrm{MCH}$

$\begin{array}{rr}1 & 5 \\ 2 & 10 \\ 3 & 20 \\ 4 & 50 \\ 5 & 100\end{array}$

MIS 34

35

36

37

$38 \quad 100$
5100.0

$10 \quad 100.0$

20100.0

$50 \quad 100.0$

100.0
100.0100 .0

100.0

100.0

100.0

100.0

100.0

100.0

100.0

100.0

100.0
100.0

96.7

100.0

100.0

100.0

90.0

100.0

100.0

96.7

96.7
3.07

Correct Match

Image Denom

Genuine Judgement Quality

Percent Percent Percent

100.0

100.0

96.7

96.7

90.0

100.0

100.0

100.0

83.3

100.0

93.3

100.0

100.0

96.7

100.0

96.7

100.0

100.0

100.0

100.0

100.0

$\begin{array}{ll}96.7 & 96.7 \\ 5.04 & 1.33\end{array}$

100.0

86.7

96.7

86.7

50.0

46.7

53.3

40.0

46.7

66.7

22.87
Mean

1.67

1.27

1.97

1.23

1.73

2.23

3.27

2.30

2.43

2.43

Laundered

Percent Percent Percent

83.3

90.0

63.3

46.7

86.7

66.7

73.3

63.3

60.0

100.0

73.3

15.49
6.7 100.0

23.3

43.3

100.0

60.0

$$
63.3
$$

36.7

83.3

100.0

$\begin{array}{rr}60.0 & 19.3 \\ 32.15 & 16.45\end{array}$
Percent Percent Percent

$$
63.3
$$

73.3

26.7

20.0

53.3

16.7

0.0

0.0

0.0

0.0

$\begin{array}{rr}25.3 & 24.3 \\ 26.84 & 36.18\end{array}$

6.7

63.3

33.3

13.3

26.7

96.7

3.3

0.0

3.3

0.0

0.0

23.3

23.3

50.0

30.0

20.0

16.7

20.0

23.3

30.3

14.26
Mean

6.27

5.60

6.57

6.70

5.60

6.13

6.20

6.67

6.30

5.47

$6.15 \mathrm{I}$

0.43

Chemical Soak

$\begin{array}{rrrllr}\text { MCH } & & & \text { Percent } & \text { Percent } & \text { Percen } \\ & 11 & 5 & 100.0 & 100.0 & 100.0 \\ & 12 & 10 & 100.0 & 100.0 & 100.0 \\ & 13 & 20 & 100.0 & 100.0 & 56.7 \\ & 14 & 50 & 100.0 & 100.0 & 100.0 \\ & 15 & 100 & 100.0 & 100.0 & 100.0 \\ \text { MIS } & 44 & 5 & 100.0 & 100.0 & 83.3 \\ & 45 & 10 & 100.0 & 100.0 & 83.3 \\ & 46 & 20 & 100.0 & 100.0 & 100.0 \\ & 47 & 50 & 100.0 & 100.0 & 100.0 \\ & 48 & 100 & 100.0 & 100.0 & 96.7\end{array}$

MEAN

ST. DEV.

$\begin{array}{rrr}100.0 & 100.0 & 90.0 \\ 0.00 & 0.00 & 13.43\end{array}$

Percent Percent Percent

93.3

86.7

50.0

76.7

83.3

36.7

33.3

43.3

40.0

33.3

$100.0 \quad 100.0$

$\begin{array}{ll}93.3 & 96.7\end{array}$

56.7

23.10
Mean

2.93

3.07

4.00

3.33

2.93

4.00

4.10

3.97

2.47

3.27

3.407

0.55 
One Crumple

\begin{tabular}{rr}
$\mathrm{MCH}$ & 16 \\
& 17 \\
18 \\
& 19 \\
& 20 \\
$\mathrm{MIS}$ & 49 \\
50 \\
51 \\
51 \\
52 \\
53 \\
\multicolumn{2}{c}{ MEAN } \\
ST. DEV.
\end{tabular}
Correct Detection

Image Denom Seal

Percent Percent Percent

$$
60.0
$$$$
50.0
$$

50.0

66.7

26.7

83.3

46.7

86.7

80.0

60.0

10.0

100.0

33.3

10.0

20.0

90.0

86.7

50.0

83.3

60.0

90.0

90.0

$30.0 \quad 100.0$

$76.7 \quad 100.0$

26.7

83.3

63.3

$\begin{array}{rrr}40.3 & 70.0 & 70.0 \\ 25.05 & 27.41 & 20.50\end{array}$
Correct Match

Image Denom Judgement Quality

Percent Percent Percent

53.3

46.7

33.3

6.7

66.7

80.0

$40.0 \quad 80.0$

53.3

50.0

0.0

0.0

3.3

30.0

0.0

0.0

6.7

0.0

3.3

0.0

19.7

21.52
56.7

50.0

50.0

63.3

53.3

30.0

26.7

23.3

30.0

30.0

40.0

13.92
Mean

5.67

5.90

6.03

5.87

5.80

6.07

6.23

6.77

6.03

5.97

6.034

0.29

Two Crumple

$\begin{array}{ll}M C H & 21 \\ & 22 \\ & 23 \\ & 24 \\ & 25 \\ \text { MIS } & 54 \\ & 55 \\ & 56 \\ & 57 \\ & 58 \\ & \end{array}$

ST. DEV.

\section{5}

10

20

50

100

5

10

20

50

100
Percent

10.0

3.3

16.7

16.7

6.7

20.0

3.3

16.7

30.0

30.0

$$
15.3
$$

9.21

$$
56.7
$$

26.93

$$
26.7
$$

83.3

43.3

20.0

70.0

60.0

26.7

90.0

100.0

50.0 t Percent

70.0

66.7

36.7

66.7

56.7

83.3

73.3

63.3

63.3

66.7

63.3

11.47
Percent Percent Percent

30.0

40.0

30.0

30.0

40.0

26.7

26.7

33.3

20.0

20.0

29.7

6.57
Mean

6.40

6.10

6.27

6.37

6.37

6.27

6.60

6.10

6.27

6.53

6.328

0.15

Four Crumple

Percent Percent Percent Percent Percent Percent

MCH 26

3.3

36.7

50.0

0.0

6.7

6.7

$28 \quad 20$

3.3

23.3

10.0

2950

$$
6.7
$$

13.3

6.7

MIS 595

$60 \quad 10$

6120

6250

63100

MEAN

ST. DEV.

13.3

0.0

0.0

3.3

3.3

0.0

43.3

0.0

50.0

0.0

0.0

0.0

16.7

16.7

10.0

3.3

13.3

$3.3 \quad 14.3 \quad 16.3$

$3.94 \quad 14.91 \quad 17.54$
$0.0 \quad 30.0$

$0.0 \quad 6.7$

$0.0 \quad 23.3$

0.0

0.0

0.0

0.0

0.0

0.0

0.0

6.7

20.0

0.0

0.0

0.0

3.3

0.0

0.0

0.00
9.0

10.65
40.0

23.3

26.7

36.7

26.7

26.7

26.7

20.0

26.7

26.7

28.0

5.62
Mean

6.53

7.00

6.83

6.97

6.60

7.00

7.00

7.00

6.93

6.93

6.879

0.17 
Counterfeited Holograms

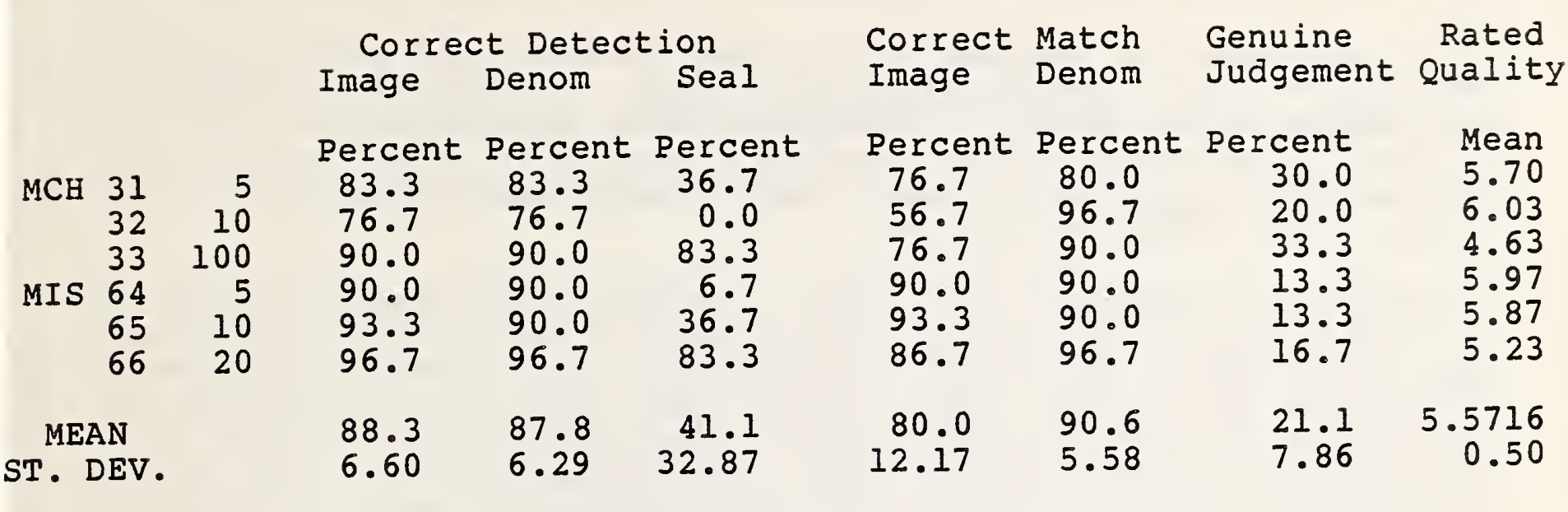




\subsection{Individual Observer Responses}

The frequency of responses for each observer was tabulated for data on detection and matching accuracy, ratings, and judgments of genuineness. Table 5 summarizes these data for each observer (identified with an arbitrary identifier and a short job classification title). Means and standard deviations are given below each column of entries.

Inspection of the data in Table 5 reveals that observers varied in the frequency with which they detected individual elements of the hologram. The degree of variability as measured by the standard deviation was similar for image and denomination detection (6.0 to 6.7 ) but larger for seal detection (9.61). The variability in the matching data was highest for the image match with four observers making 5 or more errors for the image match condition, and only one making as many as 5 errors for the denomination match category.

The variability among observers was greatest for the data on judgements of genuineness, which had a mean of 26.6 but a standard deviation of 15.7 - and a range of 6 to 55. This variability most likely reflects differences between observers in criteria for genuineness. This idea is reinforced by the smaller variability seen in the data for rated quality. These data had a standard deviation of 0.49 for the seven point scale, and a mean rating of 5.15, with no mean rating below 4.15 for any observer. Observers seemed to have less trouble determining sample quality, than they did sample genuineness.

The data given by the observers do not appear to relate to their job classification in any obvious way. Although two of the observers who made substantial errors were clerks (observers 3 and 29), two other clerks ( 11 and 28) made very few errors. A management analyst and a secretary (observers 9 and 21) both made no mismatch errors while a highly trained currency examiner (23) made several such errors, suggesting that experience with paper currency may not increase initial ability to use holograms accurately. Since no observer had had previous experience with these holograms, their performance may not be atypical of that to be expected from the general public. 
Table 5. Individual observer data

Observer

ID NO. Job Class. Image Denom Seal
Detection Accuracy
Matching Errors Matched Mismatched
Quality Judgements Image Denom Image Denom Rating Real

$\begin{array}{lllll}1 & \text { Chemist } & 36 & 45 & 45 \\ 2 & \text { Secretary } & 36 & 46 & 43 \\ 3 & \text { Clerk } & 40 & 43 & 34 \\ 4 & \text { Carpenter } & 28 & 36 & 22 \\ 5 & \text { Div. Mgr. } & 45 & 53 & 51 \\ 6 & \text { Mgt. Anal. } & 35 & 42 & 35 \\ 7 & \text { Security } & 26 & 33 & 16 \\ 8 & \text { Security } & 36 & 45 & 40 \\ 9 & \text { Mgt. Anal. } & 49 & 52 & 48 \\ 10 & \text { Secretary } & 37 & 37 & 25 \\ 11 & \text { Clerk/typ. } & 34 & 51 & 44 \\ 12 & \text { Maint Form. } & 46 & 55 & 44 \\ 13 & \text { Maint worke } & 33 & 33 & 18 \\ 14 & \text { Prod. Secur } & 36 & 47 & 42 \\ 15 & \text { Engineer } & 35 & 59 & 44 \\ 16 & \text { Elect.Eng. } & 45 & 52 & 46 \\ 17 & \text { QA Spec. } & 42 & 42 & 31 \\ 18 & \text { Press Mach. } & 46 & 49 & 48 \\ 19 & \text { Lab Tech. } & 30 & 35 & 24 \\ 20 & \text { Machinist } & 42 & 48 & 43 \\ 21 & \text { Secretary } & 36 & 45 & 41 \\ 22 & \text { Police } & 41 & 44 & 39 \\ 23 & \text { M.Cur.Exam } & 50 & 44 & 42 \\ 24 & \text { Chemist } & 42 & 54 & 50 \\ 25 & \text { Budg.Off. } & 47 & 55 & 50 \\ 26 & \text { Exam. Form. } & 32 & 39 & 29 \\ 27 & \text { Chemist } & 41 & 49 & 49 \\ 28 & \text { Prod. Clerk } & 33 & 41 & 41 \\ 29 & \text { Prod. Clerk } & 39 & 51 & 42 \\ 30 & \text { Admin Asst. } & 38 & 42 & 35 \\ & & & \end{array}$

$\begin{array}{llll}4 & 1 & 0 & 0 \\ 1 & 5 & 0 & 4 \\ 6 & 4 & 1 & 1 \\ 3 & 3 & 0 & 0 \\ 0 & 0 & 0 & 1 \\ 1 & 0 & 3 & 0 \\ 3 & 0 & 0 & 0 \\ 1 & 1 & 1 & 1 \\ 0 & 0 & 0 & 0 \\ 2 & 1 & 1 & 0 \\ 1 & 0 & 0 & 0 \\ 5 & 1 & 1 & 1 \\ 1 & 0 & 1 & 0 \\ 0 & 0 & 0 & 0 \\ 2 & 1 & 1 & 1 \\ 1 & 0 & 0 & 1 \\ 4 & 2 & 0 & 0 \\ 3 & 1 & 0 & 0 \\ 4 & 2 & 0 & 0 \\ 0 & 0 & 1 & 0 \\ 0 & 0 & 0 & 0 \\ 5 & 0 & 0 & 0 \\ 1 & 1 & 2 & 0 \\ 3 & 1 & 1 & 0 \\ 3 & 0 & 0 & 1 \\ 1 & 0 & 0 & 0 \\ 3 & 0 & 0 & 0 \\ 0 & 0 & 1 & 0 \\ 6 & 2 & 0 & 0 \\ 1 & 0 & 0 & 1 \\ & & & \end{array}$

$5.48 \quad 20$

$4.30 \quad 13$

$5.13 \quad 26$

5.3420

$5.22 \quad 27$

$5.71 \quad 42$

$5.71 \quad 24$

$4.98 \quad 8$

$4.45 \quad 28$

$5.86 \quad 11$

$5.12 \quad 16$

$4.86 \quad 38$

5.50

$4.98 \quad 54$

$4.87 \quad 23$

$5.36 \quad 54$

$5.86 \quad 12$

$4.83 \quad 55$

$5.83 \quad 6$

$4.83 \quad 25$

$5.25 \quad 10$

$5.80 \quad 13$

$4.46 \quad 46$

$4.66 \quad 47$

$4.71 \quad 24$

$5.81 \quad 8$

$4.15 \quad 52$

$4.90 \quad 27$

$5.15 \quad 15$

$5.56 \quad 46$

$\begin{array}{lrrrrrrrrr}\text { Mean } & 38.53 & 45.57 & 38.70 & 2.17 & 0.87 & 0.47 & 0.40 & 5.16 & 26 . \\ \text { St. Dev. } & 6.01 & 6.75 & 9.62 & 1.83 & 1.26 & 0.72 & 0.80 & 0.49 & 15 \text {. }\end{array}$

$\begin{array}{lrrrrrrrrr}\text { Mean } & 38.53 & 45.57 & 38.70 & 2.17 & 0.87 & 0.47 & 0.40 & 5.16 & 26 . \\ \text { St. Dev. } & 6.01 & 6.75 & 9.62 & 1.83 & 1.26 & 0.72 & 0.80 & 0.49 & 15 .\end{array}$

Total Number of Notes $=66$ 


\subsection{Comparison with Physical Measurements}

As with the data given by collins (1985): the visual performance data were compared with physical measurement data. Carter and Huber (1985) and Carter and Golden (1986) developed an optical evaluation method for measuring the physical quality of holographic images. The technique consists of shining a laser at a hologram and measuring the light diffracted froI the image along a plane of incidence. Carter and Golden used the term "diffraction efficiency" to describe the diffracted light. Initially, only specular reflections are observed as the source is moved through the plane, and then at subsequent specific angles, light is diffracted from the images encoded in the hologram. This results in discrete peaks for the image and the seal, with clearly distinguishable maxima and minima for pristine holograms. The maxima and minima can be ratioed to provide a summary measure of "diffraction efficiency".

Carter and Golden measured each of the sixty-six holograms used in the present experiment, as well as five examples of pristine holograms for each denomination. These data were examined to determine the maxima and minima for all inages and seals. Initially, two diffraction angles were selected for each hologram denomination giving the following arrangement:

\begin{tabular}{|c|c|c|c|c|c|c|c|}
\hline & Image & & & & Seal & & \\
\hline & Maximum & $45^{\circ}$ & Minimum & $28^{\circ}$ & Maximum & $16^{\circ}$ & Minimun \\
\hline & Maximum & $44^{\circ}$ & Minimum & $27^{\circ}$ & Maximum & $16^{\circ}$ & Minimum \\
\hline & Maximum & $38^{\circ}$ & Minimum & $27^{\circ}$ & Maximum & $20^{\circ}$ & Minimum \\
\hline & Maximum & $44^{\circ}$ & Minimum & $26^{\circ}$ & Maximum & $18^{\circ}$ & Minimum \\
\hline & Maximum & $46^{\circ}$ & Minimum & $36^{\circ}$ & Maximum & $21^{\circ}$ & Minimum \\
\hline
\end{tabular}

These angles reflect the scattering angle in degrees from the normal to the measurement plane. The dependent variable is the percentage of incident intensity diffracted (and measured). See Carter and Golden (1986) for a fuller description of the procedures used.

The incident intensity was determined for each of tr.e angles selected above for each denomination. The procedire worked well for all wear conditions except chemical soak, where the veaks often shifted. Here, the actual angles of maximum and minimum inciaence were used to determine intensity, rather than the oreset angle, to select physical data for comparison with the visual performance data.

Table IA of the Appendix presents the maxima, minima, and diffraction ratio data as well as the angles of maximum anu minimum incidence for the image and the seal for each note. In the pristine condition, the angular diffraction pattern shows two sharp peaks for each hologram - one for the image and one for the seal. Changes in the amplitude of the peaks and in the 
diffraction ratio had been shown to correlate with changes in visual performance for holograms on banknote currency (Mercer, 1985).

Examination of table 1 A reveals that diffraction ratios for the image ranged from 6.74 to 37.50 for pristine notes, and from 3.00 to 9.25 for chemically soaked notes. The ratios were generally at or below 1.00 for all other conditions, including counterfeit. Although the counterfeit holograms are included in this table, they were excluded from subsequent comparison with the visual performance data because they are not diffraction gratings and can not be measured adequately by Carter and Golden's procedure.

The visual performance data given in table 4 were compared with the physical data from table $1 \mathrm{~A}$. Table $2 \mathrm{~A}$ of the Appendix tabulates both the visual performance measures and the physical data. Using these data, correlation coefficients were calculated for a matrix. This matrix, given in table 6 , contains correlations between image identification (Image), image match (Imatch), quality rating (Rate), judgements of genuineness (Real), image diffraction ratio (Iratio), image diffraction maximum (Imax), image diffraction minimum (Imin), seal identification (Seal), seal diffraction ratio (Sratio), seal diffraction maximum (Smax), seal diffraction minimum (Smin), denomination identification (Denom), and denomination match (Dmatch). The six diffraction measures refer to the physical measurement data; the seven other measures refer to the visual performance measures.

Inspection of the correlation coefficients given in table 6 reveals a close correlation between several visual performance measures, as might be expected. The closest correlations are between image detection and image match (0.97) and denomination detection and match $(0.99)$. Other close correlations are found between the rating data and the detection and match data $(-0.73$ to -0.87 ). Judgements of genuineness ("real") are closely correlated only with the rating data $(-0.79)$.

The correlations between the visual and physical measurement data are highest for the rated quality data. Thus, the range of correlation coefficients between the ratings and the image diffraction data is from -0.78 to -0.82 .

On the other hand, the correlation coefficient between the data for seal detection and seal diffraction ratio is much lower, 0.40 . The correlations are equally low for the other visual performance measures - image detection, image match, denomination detection, denomination match, seal detection, and judgements of genuineness (with a range of 0.47 to 0.67 ). Thus, as with the earlier set of data, the largest correlation coefficient occurs between the data for rated quality and for the image diffraction ratio. This can be interpreted as indicating that observers 
Table 6. Matrix of correlation coefficients between physical and visual performance measures

Variable

IMAGE

IMATCH

RATE

REAL

IRATIO

IMMPX

IMMIN

SEAL

SRATIO

SMAX

SMIN

DENOH

DMATCH

IMAGE

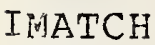

RATE

EEAL

IRATIO

I.MMAX

IMMIN

SEAL

SRATIO

SMAX

SMIN

DENOA

DMATCH

IMAGE

I IAATCH

RATE

REAL

IRATIO

I MFMAX

IMIMIN

SEAL

SRATIO

SMAX

SHIN

DENOM

DIATCH

IMAGE
1.000
0.966
-0.820
0.576
0.576
0.601
-0.620
0.517
0.402
0.264
-0.381
0.736
0.763

IRATIO

0.576

0.646

$-0.822$

0.659

1.000

0.876

$-0.682$

0.531

0.696

0.573

$-0.447$

0.472

0.505

SIMAX

0.264

0.277

$-0.449$

0.433

0.573

0.693

$-0.191$

0.283

0.823

1.000

$-0.111$

0.256

0.286

0.523

SMIN

$-0.381$

$-0.437$

0.521

$-0.293$

$-0.447$

$-0.406$

0.600

$-0.306$

$-0.356$

$-0.111$

1.000

$-0.242$

$-0.286$

Correlation Matrix

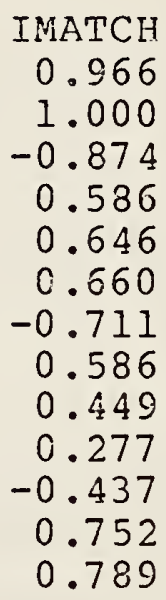

IMMIN

$-0.620$

$-0.711$

0.787

$-0.580$

$-0.682$

$-0.567$

1.000

$-0.552$

$-0.481$

$-0.191$

0.600

$-0.428$

$-0.485$

RATE

$-0.820$

$-0.874$

1.000

$-0.786$

$-0.822$

$-0.780$

0.787

$-0.760$

$-0.624$

$-0.449$

0.521

$-0.731$

$-0.764$

\section{SEAL}

0.517

0.586

$-0.760$

0.618

0.531

0.511

$-0.552$

1.000

0.403.

0.283

$-0.306$

0.725

0.731

DENOH

0.736

0.752

$-0.731$

0.532

0.472

0.494

$-0.428$

0.725

0.333

0.256

$-0.242$

1.000

0.990

DMATCH

0.763

0.789

$-0.764$

0.545

0.505

0.523

$-0.485$

0.731

0.358

0.268

$-0.286$

0.990

1.000
REAL

0.576

0.586

$-0.786$

1.000

0.669

0.591

$-0.580$

0.618

0.472

0.433

$-0.293$

0.532

0.545

SRATIO

0.402

0.449

$-0.624$

0.472

0.696

0.700

$-0.481$

0.401

1.000

0.823

$-0.356$

0.333

0.358 
relied primarily on attributes of the image quality in making their overall judgements of hologram quality, and that their judgements concurred with the diffraction data for evaluating the physical quality of the hologram.

Although the correlations between the physical and performance data are lower in the present report than in the earlier report (Mercer, 1985), this finding is not unexpected in view of the larger number of holograms compared (60 vs 21$)$, and the physical variability in the holograms themselves. For example, the maximum and minimum diffraction angles varied by as much as $10^{\circ}$ between denominations for both the image and the seal for pristine conditions and was even greater for the chemically soaked notes. In addition, the measurement technique used by Carter and Golden assesses holograms in only one viewing plane: observers can move the hologram through an infinite number of planes to maximize their likelihood of detecting the images. As a result, their performance was often better than might have been expected from the physical measurement data.

As in the previous study, it appears that diffraction ratios of less than 1.0 are associated with decreased visual performance. For such ratios the percentage of correct detections and matches decreases, while the mean quality rating increases (indicating poorer quality), as can be seen from inspection of Table $2 \mathrm{~A}$. Ratios below 1.0 can be interpreted as meaning that either no peak occurred or that background noise (scattering) was high enough to mask the peak. Visual performance appears to be somewhat better than might be predicted from the diffraction measurements in that ratios close to 1.0 are associated with reasonable accuracy - suggesting that observers were able to move the hologram in space to maximize any image/denomination/seal information. Nevertheless, ratios around 1.0 are typically associated with ratings of poor quality, indicating that observers did not consider these holograms to be effective. As a result, a diffraction ratio of 1.0 or less could be used as a physical criterion for rejecting holograms, although further research should be done to establish the best criterion for rejection. 


\section{Discussion and Conclusions}

The data obtained in the present study on the effectiveness of holograins on banknotes indicate that wear adversely affects an observer's ability to detect holographic elements and match them to banknote elements. Although some wear concitions ivere less detrimentai than others, the degrading effects of wear were significant even for the one crumple condition. In addition, laundering, a commonly occurring consumer abuse, destroyed the ability to natch the denomination on 8 of the 10 laundered notes. The only wear condition which did not adversely affect performance was the 30 minute soak in ethanol - a relatively innocuous cherilical test. As in the previcus study (Collins, 1985), performance was particularly poor for the Frank]in hologram with observers making many more matching resconse errors for it than for any other hologram.

The data presented in section 3 do not support the riypothesis that holograms can pass the same wear tests that banknote currency does. The effect of even minimal wear, exemplified by the one crumple test, is to reduce matching accuracy - the critical performance attribute for holograms - weil below the 80 percent criterion set forth in the previous report. While the accuracy of matching images for notes in the pristine concition is 96.7 percent, it drops to 19.7 percent for the one crumrie conaition. By the four crumple condition, observers fail to match any image accurately; and only match denominations with a accuracy of 9 percent. Yet, conventional banknote currency is considered acceptable after 32 crumples.

The only conditions in which either detection frecuency or matching accuracy are above 80 percent correct are the oristine and chemical soak conditions. It should be noted that overail performance would have been much poorer had a more stringent chemical soak condition than a 30-min soak in ethanol been usec. some test soaks with chemicals such as acetone or sodium hydroxide had obliterated the holograms so completely that they could not be included in the present experiment.

As a result, it is reasonable to conciude that the particuler set of holograms studied did not adequately withstand even minimal wear tests.

The data obtained in the present study further suggest that use of a holographic image of a portrait as an incicator of genuineness was not particularly successful. Coservers made many more errors matching the image to the portrait than they did for the counter. In addition, they detected both the inage and the seal less frequently than the counter.

The fact that observers made many more matching errors ( 85 vs 22) for matched notes than for mismatched notes suggests they had 
some difficulty in determining if the holographic image really represented the same person as the note portrait. Further support for this idea is given by the fact that observers made errors 2.6 times more frequently for the image match than for the denomination match. These data suggest that it may be easier to tell that two denominations are the same than that two images match.

The observers also made a much greater number of errors for the Franklin hologram - portrait combination. They had far more trouble determining that the two Franklins matched than they did for all other images/portraits combined. The converse was not true - observers did not claim the Franklin hologram matched a different portrait. This finding reinforces the need to ensure the fidelity of the holographic image relative to that of the portrait, since informal examination of the hologram suggested that it really did not look like the Franklin portrait. In addition, the physical diffraction ratios were lower for Franklin, even in the pristine condition. The problems with the Franklin hologram also suggest that the quality of the image in the hologram needs to be a particularly accurate representation of the portrait if observers are to use holograms successfully as a counterfeit deterrent. Otherwise, the hologram becomes a poor quality counterfeit of the portrait - effectively degrading the effectiveness of both portrait and hologram.

The data further suggest that observers used unanticipated criteria for genuineness. Ideally, they should have considered only the six "fake" holograms as counterfeit. The data indicate clearly, however, that they considered a mismatch between hologram and note elements to be a major indicator of a counterfeit note - the original reason for using holograms as a counterfeit deterrent. Observers also tended to consider worn notes, particularly those in which elements could not be matched, to be counterfeit. A similar tendency to consider worn bills as counterfeit was found in a report on counterfeit currency (Collins, Mayerson, and Worthey, 1985). In the present report, the mean percentage of indicating notes as genuine drop from a high of 66.7 percent for pristine to 30.3 and 28.0 percent for notes in the laundered and four crumple conditions, respectively.

Nonetheless, the counterfeited holograms were seen as counterfeit far more frequently than any other group of notes, with the mismatched "fake" notes having a very low rate of acceptance as genuine (around 15 percent).

The data reinforce the conclusion from the previous report (Collins, 1985) that wear seriously degrades the performance of holograms relative to the rest of the note. As with the OVDS's studied in that report, the holograms studied here failed wear tests that normal banknote currency easily passes. 


\section{Recornmenàations}

Based on the data obtained in the present report and in the previous report (Collins, 1985), the five holograms stuaied should not be used on banknotes. All have consistently failed visual performance tests related to detection, identification, and matching when subjected to even minimal wear. Furthermore, they are consistently given low ratings for quality and are not considered genuine once they are no longer in the pristine condition.

The improvements made in the holograms between July 1985 anc January 1986 did not improve their performance on visual. performance tests. Rather, the newer holograms could not be accurately matched with other note elements even in the one crumple condition. Contrary to expectations, the detectability of the holographic image was even poorer than that of the denomination counter. This suggests that it is more difeicult to aevelop readily detectable holographic images of faces than of numerals - an iciea reinforced by the greater number of errors made for the Franklin holographic image. Observers also had more trouble matching the images - successfully making matches in only 51 percent of the notes. The holograms, particularly the holographic images; thus appear to be difficult to use as an indicator of currency genuineness after being subjected to any wear test. In addition, once subjected to the various wear tests, they were ratea as being of poor quality - a rating which correlated closely with physical measurements of difiraction efficiency. As a result, hologramis do not appear to be an effecive tool for ensuring visual detection of counterfeit paper currency.

Finaliy, it should be remembered that the observers, while not familiar with holograms, were relatively young and skilleci workers. Although they had had no training with holograms, as employees of the Bureau of Engraving and Printing, they may have had somewhat greater exposure to banknote currency. Yet, although the variability between the BEP observers was larger, it did not appear to be related to their job description or apparent familiarity with paper currency. Nevertheless, performance coulci reasonably be expected to be even poorer with oicier, iess skilied, or handicapped observers.

Consequently, the use of the holograms as they are presently designed cannot be recommendeä for use as a counterfeit cieterrent on paper currency. 


\section{References}

Bureau of Engraving and Printing. BEP Test Method RT-86-01, Crumple Test. BEP Test Method RT-86-02, Chemical Resistance. BEP Test Method RT-86-03, Laundering.

Carter, W.H. \& Golden, J.P. Measurements of Wear in Optically Variable Devices. Washington, D.C. Naval Research Laboratory Report 8992, June 1986.

Carter, W.H., \& Huber, V. Measurements of Wear in Optically Variable Devices. Letter Report from the Naval Research Laboratory to the Bureau of Engraving and Printing, June 1985.

Collins, B.L. Visual Assessment of Optically Variable Devices. Letter Report from the National Bureau of Standards to the Bureau of Engraving and Printing, July, 1985.

Collins, B.L., Mayerson, S., Worthey, J.A. Noticeability of Features of Secure Documents. Gaithersburg, MD., National Bureau of Standards, NBSIR 85-3160, July 1985.

Mercer. J.W. Evaluation of Holographic OVDs. Internal Memorandum to E.L. Graminski, Bureau of Engraving and Printing, July 1985.

Natrella, M. Experimental Statistics. Washington D.C., National Bureau of Standards, Handbook 91, 1963. 
Appendi.x A

Figures Depicting Visual Performance Data and Tables Containing Physical Measurement Data 
Legend

PM refers to pristine matched; PMIS to pristine mismatched; LM to laundered matched; LMIS to laundered mismatched; CSM to chemical soak matched; CSMIS to chemical soak mismatched; IXM to one crumple matched; IXMIS to one crumple mismatched; $2 \times M$ to two crumple matched; 2 XMIS to two crumple mismatched; $4 \mathrm{XM}$ to four crumple matched; 4 XMIS to four crumple mismatched; CM to counterfeit matched; and CMIS to counterfeit mismatched.

IMAGE. DENOM. SEAL DETECTION

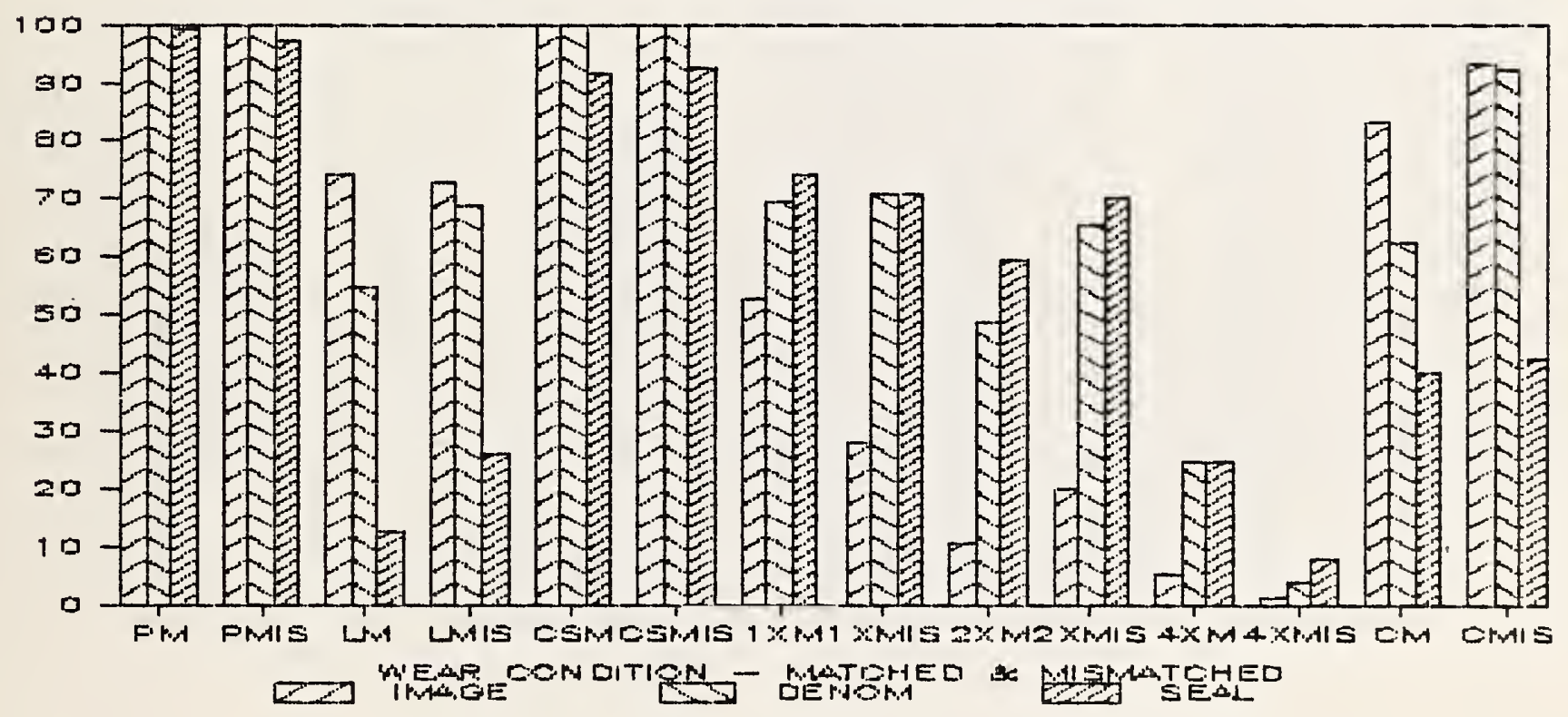

Figure la. Percentage of correct detection of the three holographic elements, image, denomination counter, and seal as a function of wear condition. Data for image detection are given first, followed by the denomination and seal data. 


\section{Legend}

FM refers to pristine matched; PHIS to pristine mismatched; LM to laundered matched; LMIS to laundered mismatched; CSMi to chemical soak matched; CSMIS to chemical soak mismatched; $1 \times$ m to one crumple matched; IXMIS to one crumple mismatched; $23 \mathrm{mil}$ to two crumple matched; $2 X M I S$ to two crumple mismatched; 4 XH to four crumple matched; 4XMIS to four crumple mismatched; Cir to counterfeit matched; and ChIS to counterfeit mismatched.

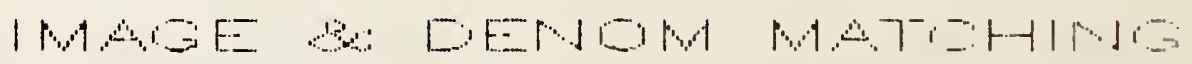

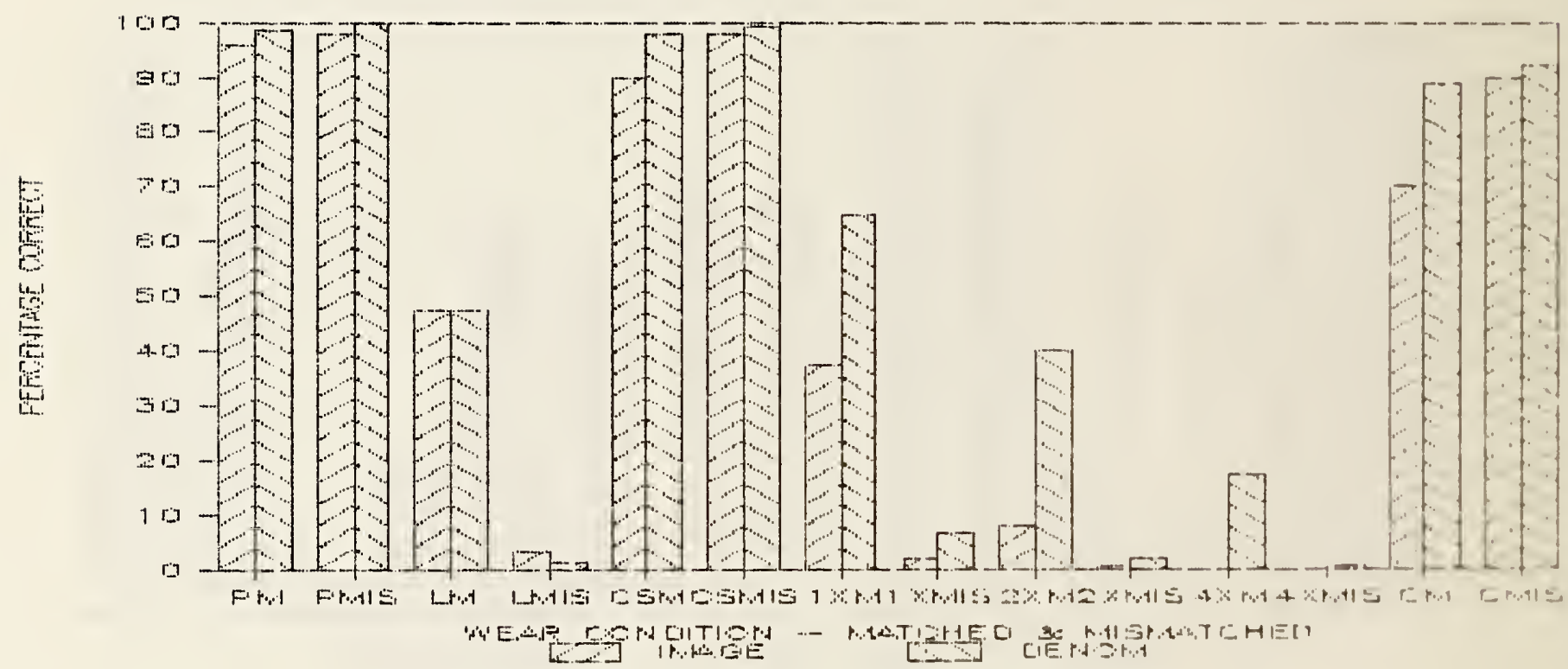

Figure 2a. Percentage of correct matches between hoioglám iniage and note portrait and hologram denomination counter and note denomination counter for all notes as a function of wear condition. Data for the image match are given first followeci by the data for the denomination natch. 


\section{Legend}

PRIS refers to pristine notes; LD to laundered notes: CS to chemically soaked notes; $1 \mathrm{x}$ to one crumpled notes; $2 \mathrm{x}$ to two crumpled notes; $4 \mathrm{X}$ to four crumpled notes; and CTF to counterfeit notes.

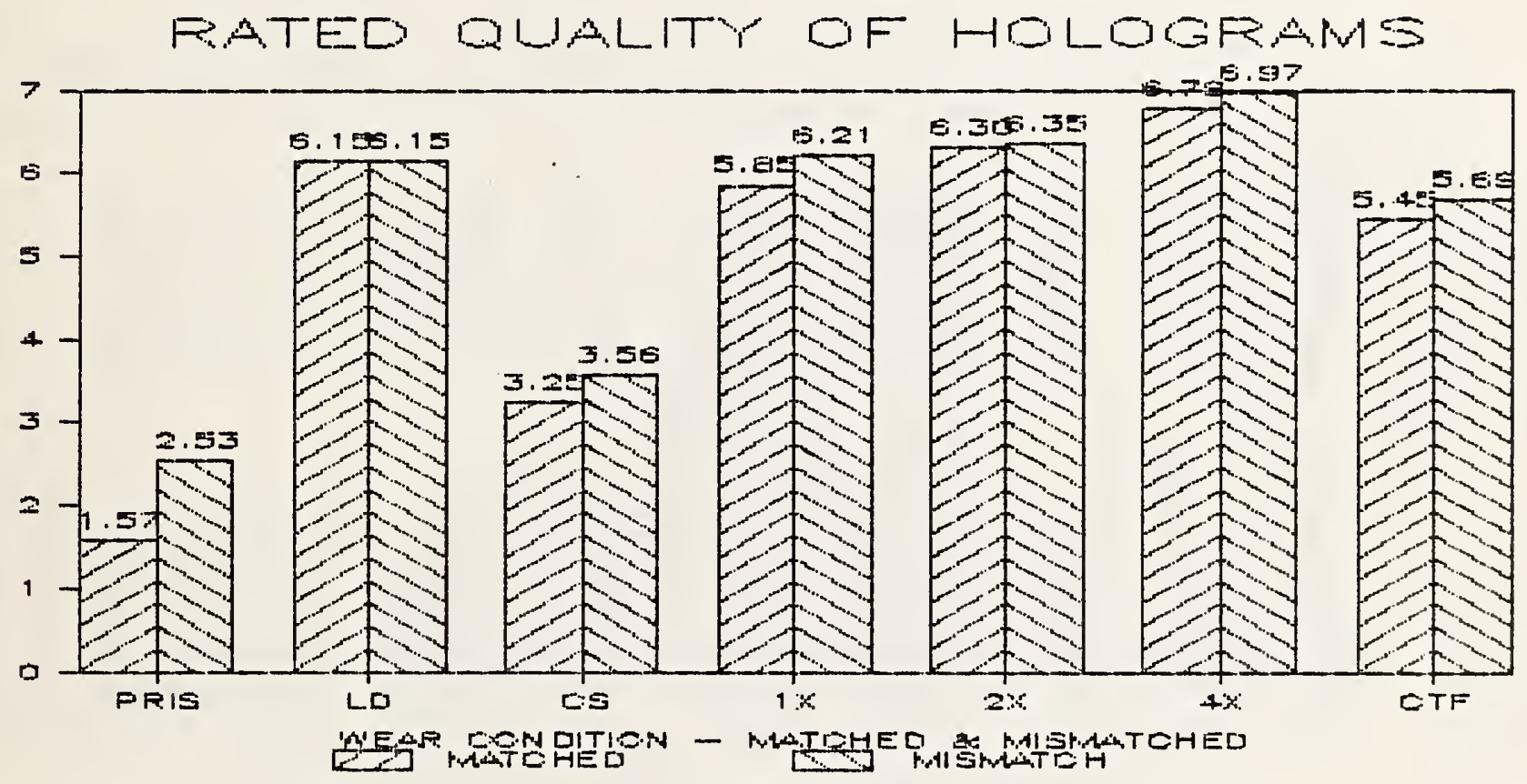

Figure $3 a$. Mean ratings of hologram quality as a function of wear condition. The first entry in a wear condition refers to matched notes; the second to mismatched notes. 


\section{Legend}

PRIS refers to pristine notes; LD to laundered notes: CS to chemically soaked notes; $1 \mathrm{x}$ to one crumpled notes; $2 \mathrm{x}$ to two crumplea notes; $4 X$ to four crumpled notes; ana CTF to counterfeit notes.

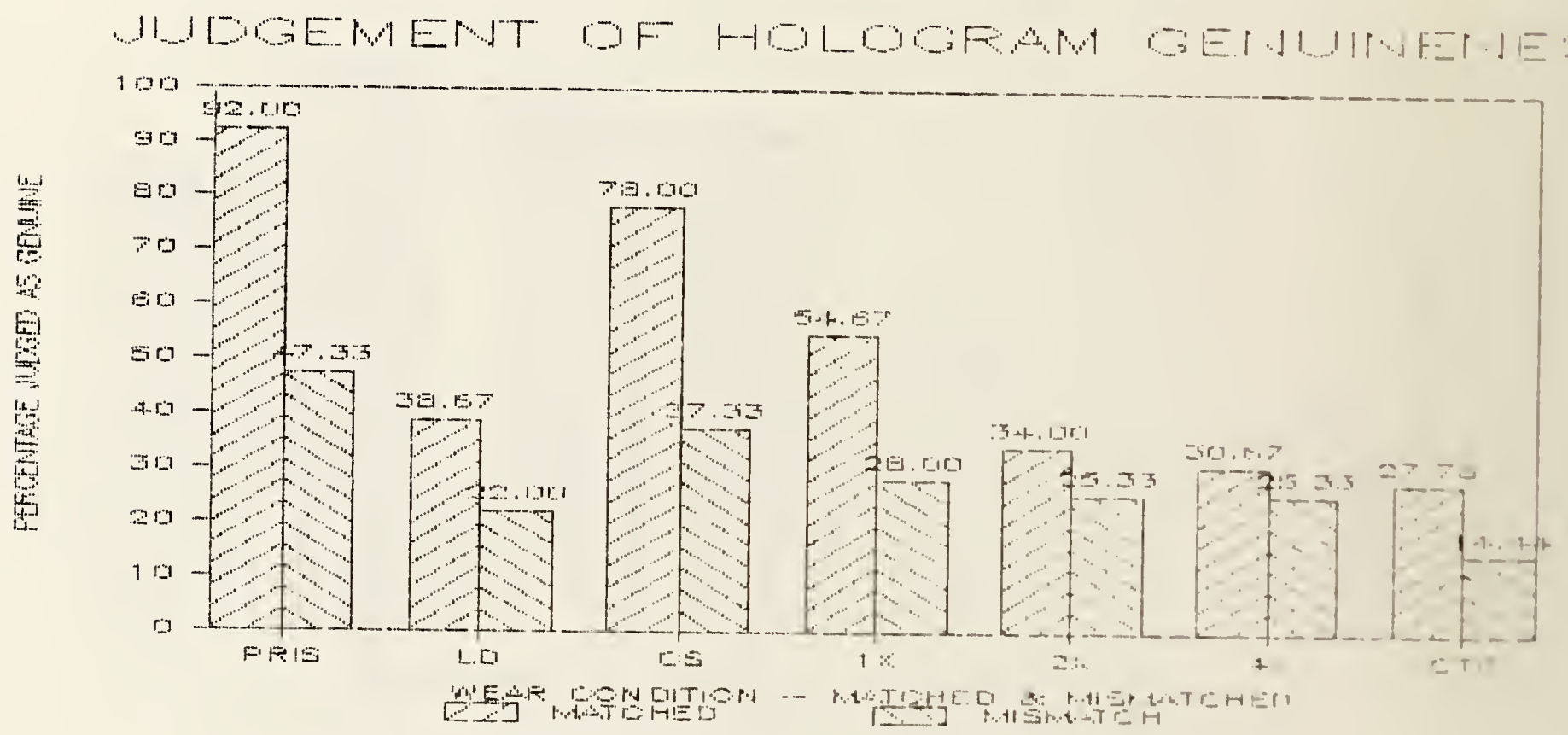

Figure 4 a. Percentage of notes rated as genuine as a functicn of wear condition. The first entry in a wear concition lefers to matched notes; the secona to mismatched notes. 
Table 1A. Physical Measurement Data - Diffraction Response

IMAGE

SEAL

\begin{tabular}{|c|c|c|c|c|c|c|c|c|c|c|}
\hline NOTE & MAX & $\begin{array}{l}\text { ANGLE/ } \\
\text { DEGRE }\end{array}$ & MIN & $\begin{array}{l}\text { ANGLE } \\
\text { DEGREE }\end{array}$ & RATIO & MAX & $\begin{array}{l}\text { ANGLE/ } \\
\text { DEGREE }\end{array}$ & $M I N$ & $\begin{array}{l}\text { ANGLE, } \\
\text { DEGRE }\end{array}$ & E/ RATIO \\
\hline $\begin{array}{ll}V E & 5 \\
V E & 10 \\
V E & 20 \\
V E & 50 \\
V E & 100\end{array}$ & $\begin{array}{l}0.081 \\
0.069 \\
0.119 \\
0.163 \\
0.069\end{array}$ & $\begin{array}{l}56 \\
55 \\
49 \\
55 \\
59\end{array}$ & $\begin{array}{l}0.003 \\
0.003 \\
0.005 \\
0.005 \\
0.003\end{array}$ & $\begin{array}{l}45 \\
44 \\
38 \\
44 \\
46\end{array}$ & $\begin{array}{l}27.00 \\
23.00 \\
26.44 \\
32.60 \\
27.60\end{array}$ & $\begin{array}{l}0.054 \\
0.043 \\
0.042 \\
0.034 \\
0.052\end{array}$ & $\begin{array}{l}28 \\
27 \\
27 \\
26 \\
36\end{array}$ & $\begin{array}{l}0.005 \\
0.005 \\
0.006 \\
0.006 \\
0.003\end{array}$ & $\begin{array}{l}16 \\
16 \\
20 \\
18 \\
21\end{array}$ & $\begin{array}{r}10.80 \\
8.60 \\
7.00 \\
5.67 \\
17.33\end{array}$ \\
\hline & & & & & 27.328 & & & & & 9.8 \\
\hline
\end{tabular}

PRISTINE

MATCHED NOTES

$\begin{array}{lrllllllllr}\text { TN1D5 } & 0.070 & 56 & 0.004 & 45 & 19.91 & 0.045 & 28 & 0.008 & 16 & 5.65 \\ \text { TN2D10 } & 0.075 & 55 & 0.002 & 44 & 37.50 & 0.033 & 27 & 0.004 & 16 & 8.25 \\ \text { TN3D20 } & 0.147 & 49 & 0.005 & 38 & 32.67 & 0.067 & 27 & 0.011 & 16 & 6.38 \\ \text { TN4D50 } & 0.188 & 55 & 0.006 & 44 & 31.33 & 0.188 & 26 & 0.006 & 18 & 31.33 \\ \text { TNSD100 } & 0.065 & 59 & 0.004 & 46 & 16.25 & 0.067 & 36 & 0.005 & 21 & 13.40 \\ \text { MEAN } & & & & & & & & & & \end{array}$

LAUNDERED

TN6D5

TN7DIO

TN8D20

TN9D50

TN10D100

MEAN

CHEMICAL SOAK
TNIID5

TN12DI0

TN13D20

TNI 4D50

TN15D100

MEAN
0.01256

$0.012 \quad 55$

$0.020 \quad 49$

0.03455

0.01159
$0.014 \quad 45$

$0.013 \quad 44$

0.020

0.038

0.013

38

44

46

$$
0.86
$$

0.92

0.022

1.00

0.023

0.028

0.89

0.049

0.85

0.015

0.9042

28

27

0.041

0.041

27

0.045

26

0.072

36

0.03418

21

0.5683

0.54

0.56

0.62

0.68

0.44

ONE CRUMPLE
TN16D5

TNI7DI0

TN18D20

TN19D50

TN20D100

$$
\begin{array}{ll}
0.031 & 55 \\
0.025 & 54 \\
0.076 & 49 \\
0.049 & 55 \\
0.033 & 58
\end{array}
$$

$0.007 \quad 41$

$0.007 \quad 42$

0.00938

0.01239

0.01145

$\begin{array}{lll}4.43 & 0.019 & 28 \\ 3.57 & 0.016 & 27 \\ 8.44 & 0.022 & 27 \\ 4.08 & 0.018 & 26 \\ 3.00 & 0.043 & 35\end{array}$

4.7055
0.01321

0.01322

$0.012 \quad 22$

0.01721

0.01426
1.46

1.23

1.83

1.06

3.07

1.7311
0.015

0.027

0.032

0.184

0.024
22
16
20
18
21

1.50

1.24

0.81

0.20

0.50 
TWO CRUMPLE

$\begin{array}{llllllllll}\text { TN21D5 } & 0.010 & 56 & 0.016 & 45 & 0.59 & 0.021 & 28 & 0.034 & 16 \\ \text { TN22D10 } & 0.011 & 55 & 0.014 & 44 & 0.81 & 0.030 & 27 & 0.034 & 16 \\ \text { TN23D20 } & 0.015 & 49 & 0.020 & 38 & 0.75 & 0.027 & 27 & 0.041 & 20 \\ \text { TN24D50 } & 0.016 & 55 & 0.019 & 44 & 0.84 & 0.020 & 26 & 0.032 & 16 \\ \text { TN25D1C0 } & 0.018 & 56 & 0.018 & 45 & 1.00 & 0.018 & 36 & 0.043 & 21\end{array}$
0.63 0.86 .67 .62 0.42

MEAN

0.3001

FOUR CRUMPLE

$\begin{array}{llllllllll}\text { TN26D5 } & 0.012 & 56 & 0.015 & 45 & 0.80 & 0.020 & 28 & 0.027 & 16 \\ \text { TN27D10 } & 0.012 & 55 & 0.013 & 44 & 0.92 & 0.024 & 27 & 0.045 & 16 \\ \text { TN28D20 } & 0.014 & 49 & 0.018 & 38 & 0.78 & 0.022 & 27 & 0.022 & 20 \\ \text { TN29D50 } & 0.013 & 55 & 0.016 & 44 & 0.81 & 0.025 & 26 & 0.025 & 18 \\ \text { TN30D100 } & 0.015 & 56 & 0.018 & 45 & 0.81 & 0.003 & 36 & 0.047 & 21\end{array}$

MEAN

0.8237

0.6665

COUNTERFEIT

$\begin{array}{llllllllll}\text { TN31D5 } & 0.003 & 56 & 0.003 & 45 & 1.00 & 0.004 & 28 & 0.010 & 16 \\ \text { TN32D10 } & 0.004 & 55 & 0.003 & 44 & 1.33 & 0.005 & 27 & 0.009 & 16 \\ \text { TN33D100 } & 0.003 & 56 & 0.002 & 45 & 1.50 & 0.003 & 36 & 0.006 & 21\end{array}$

0.35

0.56

0.55

MEAN

1.2777

0.4836

PRISTINE

MISMATCHED NOTES

TN35010-20 $0.090 \quad 49$

0.003

0.005

0.005

0.004

0.007

0.06256

TN37D5C-5

TN38D100-1C

MEAN

LAUNDERED

TN39D5-50

$$
0.025 \quad 55
$$

0.019

44

1.32

0.023

26

0.036

45

44

0.016

TN4 1D20-10

0.01455

TN42D50-100

0.01456

TN43D100-2C

0.017

49

MEAN

0.015

0.016

45

36

$0.87 \quad 0.024$

$\begin{array}{ll}0.84 & 0.027\end{array}$

28

27

0.054

0.95

0.015

36

1.06

0.019

27

0.04

0.027

0.024

1.0080

$0.60 \div 6$

CHEMICAL SOAK

TN44D5-10 $0.030 \quad 55$

$0.005 \quad 40$

$6.00 \quad 0.014$

27

0.012

22

$8.90 \quad 0.040$

27

0.016

$0.004 \quad 40$

9.25

0.016

28

0.009

0.007

0.007

45

7.54

0.048

36

26
11.91

3.17

2.86

24.00

1.76

8.7384
TIS48D100-50 $0.088 \quad 55$

0.64

0.44

0.61

0.56

0.77

0.01320

1.17

2.50

1.78

6.79

2.62

MEAN 
TN49D5-50

IN50D10-5

TN51D 20-100

TN52D50-10

IN53D10-20

MEAN

TWO CRUMPLE

TN54D5-100

TN55D10-5

TN56D 20-50

TN57D50-20

IN58D100-10

$0.014 \quad 55$

0.01356

0.01356

0.01255

$0.016 \quad 49$
$0.021 \quad 44$

$0.014 \quad 45$

$0.013 \quad 45$

$0.023 \quad 44$

0.02438

0.7595
0.72

0.58

0.67

1.15

0.95

0.8131

$0.013 \quad 45$

$0.92 \quad 0.014$

$\begin{array}{ll}0.88 & 0.027\end{array}$

$\begin{array}{lll}36 & 0.046 & 21\end{array}$

$\begin{array}{lll}28 & 0.037 & 16\end{array}$

$\begin{array}{lll}26 & 0.025 & 18\end{array}$

$\begin{array}{lll}27 & 0.032 & 20\end{array}$

$\begin{array}{lll}27 & 0.065 & 16\end{array}$

0.6778
0.8088

$0.83 \quad 0.030$

$0.56 \quad 0.042$

$\begin{array}{ll}0.018 & 38 \\ 0.018 & 44\end{array}$

$$
0.8088
$$

.

MEAN 
Table 2A. Comparison of Physical Measurement Data with Visual Performance Data

Note Image Imatch Rate Real Iratio Immax Immin Sratio Smax Smin Seal

\begin{tabular}{|c|c|c|c|c|c|c|c|c|c|c|}
\hline $\begin{array}{l}1.00 \\
1.00 \\
1.00 \\
1.00 \\
1.00\end{array}$ & $\begin{array}{l}1.00 \\
1.00 \\
0.97 \\
1.00 \\
0.83\end{array}$ & $\begin{array}{l}1.67 \\
1.27 \\
1.97 \\
1.23 \\
1.73\end{array}$ & $\begin{array}{l}0.90 \\
1.00 \\
0.87 \\
0.97 \\
0.87\end{array}$ & $\begin{array}{l}19.91 \\
37.50 \\
32.67 \\
31.33 \\
16.25\end{array}$ & $\begin{array}{l}0.070 \\
0.075 \\
0.147 \\
0.188 \\
0.065\end{array}$ & $\begin{array}{l}0.004 \\
0.002 \\
0.005 \\
0.006 \\
0.004\end{array}$ & $\begin{array}{r}5.55 \\
8.25 \\
6.38 \\
31.33 \\
13.40\end{array}$ & $\begin{array}{l}0.045 \\
0.033 \\
0.067 \\
0.188 \\
0.067\end{array}$ & $\begin{array}{l}0.008 \\
0.004 \\
0.011 \\
0.006 \\
0.005\end{array}$ & $\begin{array}{l}1.00 \\
1.00 \\
0.97 \\
1.00 \\
1.00\end{array}$ \\
\hline $\begin{array}{l}0.83 \\
0.90 \\
0.63 \\
0.47 \\
0.87\end{array}$ & $\begin{array}{l}0.63 \\
0.73 \\
0.27 \\
0.20 \\
0.53\end{array}$ & $\begin{array}{l}6.27 \\
5.60 \\
6.57 \\
6.70 \\
5.60\end{array}$ & $\begin{array}{l}0.33 \\
0.33 \\
0.23 \\
0.23 \\
0.50\end{array}$ & $\begin{array}{l}0.86 \\
0.92 \\
1.00 \\
0.89 \\
0.85\end{array}$ & $\begin{array}{l}0.012 \\
0.012 \\
0.020 \\
0.034 \\
0.011\end{array}$ & $\begin{array}{l}0.014 \\
0.013 \\
0.020 \\
0.038 \\
0.013\end{array}$ & $\begin{array}{l}0.54 \\
0.56 \\
0.62 \\
0.68 \\
0.44\end{array}$ & $\begin{array}{l}0.022 \\
0.023 \\
0.028 \\
0.049 \\
0.015\end{array}$ & $\begin{array}{l}0.041 \\
0.041 \\
0.045 \\
0.072 \\
0.034\end{array}$ & $\begin{array}{l}0.00 \\
0.07 \\
0.10 \\
0.13 \\
0.33\end{array}$ \\
\hline $\begin{array}{l}1.00 \\
1.00 \\
1.00 \\
1.00 \\
1.00\end{array}$ & $\begin{array}{l}0.90 \\
0.90 \\
0.97 \\
1.00 \\
0.73\end{array}$ & $\begin{array}{l}2.93 \\
2.67 \\
4.00 \\
3.33 \\
2.93\end{array}$ & $\begin{array}{l}0.93 \\
0.87 \\
0.50 \\
0.77 \\
0.83\end{array}$ & $\begin{array}{l}3.63 \\
3.13 \\
8.44 \\
3.06 \\
2.82\end{array}$ & $\begin{array}{l}0.029 \\
0.025 \\
0.076 \\
0.049 \\
0.031\end{array}$ & $\begin{array}{l}0.008 \\
0.008 \\
0.009 \\
0.016 \\
0.011\end{array}$ & $\begin{array}{l}1.12 \\
0.80 \\
1.69 \\
0.82 \\
2.47\end{array}$ & $\begin{array}{l}0.019 \\
0.016 \\
0.022 \\
0.018 \\
0.042\end{array}$ & $\begin{array}{l}0.017 \\
0.020 \\
0.013 \\
0.022 \\
0.017\end{array}$ & $\begin{array}{l}1.00 \\
1.00 \\
0.57 \\
0.93 \\
1.00\end{array}$ \\
\hline $\begin{array}{l}0.60 \\
0.50 \\
0.27 \\
0.47 \\
0.80\end{array}$ & $\begin{array}{l}0.53 \\
0.33 \\
0.07 \\
0.40 \\
0.53\end{array}$ & $\begin{array}{l}5.67 \\
5.70 \\
6.03 \\
5.87 \\
5.80\end{array}$ & $\begin{array}{l}0.57 \\
0.50 \\
0.50 \\
0.63 \\
0.53\end{array}$ & $\begin{array}{l}1.15 \\
1.00 \\
0.65 \\
1.00 \\
1.25\end{array}$ & $\begin{array}{l}0.015 \\
0.012 \\
0.015 \\
0.020 \\
0.015\end{array}$ & $\begin{array}{l}0.013 \\
0.012 \\
0.023 \\
0.020 \\
0.012\end{array}$ & $\begin{array}{l}0.50 \\
0.70 \\
0.81 \\
0.20 \\
0.50\end{array}$ & $\begin{array}{l}0.016 \\
0.019 \\
0.026 \\
0.036 \\
0.012\end{array}$ & $\begin{array}{l}0.032 \\
0.027 \\
0.032 \\
0.184 \\
0.024\end{array}$ & $\begin{array}{l}0.90 \\
0.87 \\
0.50 \\
0.83 \\
0.60\end{array}$ \\
\hline $\begin{array}{l}0.10 \\
0.03 \\
0.17 \\
0.17 \\
0.07\end{array}$ & $\begin{array}{l}0.00 \\
0.10 \\
0.13 \\
0.10 \\
0.07\end{array}$ & $\begin{array}{l}6.40 \\
6.10 \\
6.27 \\
5.37 \\
6.37\end{array}$ & $\begin{array}{l}0.30 \\
0.40 \\
0.30 \\
0.30 \\
0.40\end{array}$ & $\begin{array}{l}0.59 \\
0.81 \\
0.75 \\
0.84 \\
1.00\end{array}$ & $\begin{array}{l}0.010 \\
0.011 \\
0.015 \\
0.016 \\
0.018\end{array}$ & $\begin{array}{l}0.016 \\
0.014 \\
0.020 \\
0.019 \\
0.018\end{array}$ & $\begin{array}{l}0.63 \\
0.68 \\
0.67 \\
0.62 \\
0.42\end{array}$ & $\begin{array}{l}0.021 \\
0.030 \\
0.027 \\
0.020 \\
0.018\end{array}$ & $\begin{array}{l}0.034 \\
0.034 \\
0.041 \\
0.032 \\
0.043\end{array}$ & $\begin{array}{l}0.70 \\
0.67 \\
0.37 \\
0.67 \\
0.57\end{array}$ \\
\hline $\begin{array}{l}0.03 \\
0.00 \\
0.03 \\
0.07 \\
0.13\end{array}$ & $\begin{array}{l}0.00 \\
0.00 \\
0.00 \\
0.00 \\
0.00\end{array}$ & $\begin{array}{l}6.53 \\
7.00 \\
6.83 \\
6.97 \\
6.60\end{array}$ & $\begin{array}{l}0.40 \\
0.23 \\
0.27 \\
0.37 \\
0.27\end{array}$ & $\begin{array}{l}0.80 \\
0.92 \\
0.78 \\
0.81 \\
0.81\end{array}$ & $\begin{array}{l}0.012 \\
0.012 \\
0.0114 \\
0.013 \\
0.015\end{array}$ & $\begin{array}{l}0.015 \\
0.013 \\
0.018 \\
0.016 \\
0.018\end{array}$ & $\begin{array}{l}0.73 \\
0.53 \\
1.00 \\
1.00 \\
0.07\end{array}$ & $\begin{array}{l}0.020 \\
0.024 \\
0.022 \\
0.025 \\
0.003\end{array}$ & $\begin{array}{l}0.027 \\
0.045 \\
0.022 \\
0.025 \\
0.047\end{array}$ & $\begin{array}{l}0.50 \\
0.07 \\
0.10 \\
0.07 \\
0.50\end{array}$ \\
\hline
\end{tabular}


Note Image Imatch Rate Real Iratio Immax Immin

$\begin{array}{rrrrrrrr}34 & 1.00 & 1.00 & 2.23 & 0.50 & 11.67 & 0.035 & 0.003 \\ 35 & 1.00 & 0.93 & 3.27 & 0.47 & 18.00 & 0.090 & 0.005 \\ 36 & 1.00 & 1.00 & 2.30 & 0.53 & 11.88 & 0.095 & 0.008 \\ 37 & 1.00 & 1.00 & 2.43 & 0.40 & 15.50 & 0.062 & 0.004 \\ 38 & 1.00 & 1.00 & 2.43 & 0.47 & 6.29 & 0.044 & 0.007\end{array}$

$\begin{array}{lll}39 & 0.67 & 0.30 \\ 40 & 0.73 & 0.70 \\ 41 & 0.63 & 0.47 \\ 42 & 0.60 & 0.60 \\ 43 & 1.00 & 1.00\end{array}$

$6.13 \quad 0.30$

$6.20 \quad 0.20$

$\begin{array}{lll}6.67 & 0.17\end{array}$

6.300 .20

$\begin{array}{lll}5.47 & 0.23\end{array}$

$\begin{array}{lll}1.32 & 0.025 & 0.019\end{array}$

$\begin{array}{lll}0.87 & 0.013 & 0.015\end{array}$

$0.84 \quad 0.014 \quad 0.016$

$\begin{array}{lll}0.95 & 0.014 & 0.015\end{array}$

$\begin{array}{lll}1.06 & 0.017 & 0.016\end{array}$

44
45
46
47
48

$1.00 \quad 1.00$

$1.00 \quad 0.93$

$4.00 \quad 0.37$

$4.10 \quad 0.33$

3.100 .43

1.00

1.00

$1.00 \quad 0.97$

2.470 .40

$3.27 \quad 0.33$

4.29

8.80

5.69

6.00

9.25

$0.030 \quad 0.007$

$0.088 \quad 0.010$

0.0370 .007

$\begin{array}{lll}0.039 & 0.007\end{array}$

0.0880 .010

49

50

5

5

53

5

55

57

5

580

$\begin{array}{llll}0.10 & 5.87 & 0.30\end{array}$

0.67

0.0140 .021

0.93

$0.013 \quad 0.014$

0.13

0.10

$\begin{array}{lll}6.23 & 0.27\end{array}$

$\begin{array}{lll}6.77 & 0.23\end{array}$

1.00

0.0130 .013

$\begin{array}{lll}6.03 & 0.30\end{array}$

0.52

0.0120 .023

$0.016 \quad 0.024$

$\begin{array}{lll}0.53 & 5.97 & 0.30\end{array}$

0.68

$\begin{array}{lll}6.27 & 0.27\end{array}$

6.600 .27

0.92

0.88

0.0120 .013

$\begin{array}{ll}0.03 & 0.07\end{array}$

6.100 .33

0.86

0.83

6.270 .20

0.0140 .016

0.0180 .021

0.0150 .018

5

6

6

$6]$

63
0.56

$0.010 \quad 0.018$

$\begin{array}{lll}6.53 & 0.20\end{array}$

$\begin{array}{llll}0.78 & 0.014 & 0.018\end{array}$

$\begin{array}{llll}0.79 & 0.011 & 0.014\end{array}$

$\begin{array}{lll}0.82 & 0.012 & 0.014\end{array}$

$\begin{array}{lll}0.73 & 0.012 & 0.017\end{array}$

0.82

$\begin{array}{lll}0.014 & 0.017\end{array}$

Sratio Smax Smin Seal

$11.910 .054 \quad 0.005 \quad 1.00$

$\begin{array}{llllll}3.17 & 0.019 & 0.006 & 0.90\end{array}$

$\begin{array}{lllll}2.86 & 0.020 & 0.007 & 1.00\end{array}$

$\begin{array}{lllll}24.00 & 0.048 & 0.002 & 1.00\end{array}$

$\begin{array}{llllll}1.10 & 0.023 & 0.021 & 0.97\end{array}$

$\begin{array}{lllll}0.64 & 0.023 & 0.036 & 0.27\end{array}$

$\begin{array}{lllll}0.44 & 0.024 & 0.054 & 0.10\end{array}$

$\begin{array}{llllll}0.61 & 0.027 & 0.044 & 0.03\end{array}$

$\begin{array}{lllll}0.56 & 0.015 & 0.027 & 0.37\end{array}$

$\begin{array}{lllll}0.77 & 0.019 & 0.024 & 0.53\end{array}$

$\begin{array}{llllll}0.82 & 0.014 & 0.017 & 0.83\end{array}$

$\begin{array}{lllll}2.50 & 0.040 & 0.016 & 0.83\end{array}$

$\begin{array}{lllll}1.33 & 0.016 & 0.012 & 1.00\end{array}$

$\begin{array}{llllll}6.79 & 0.048 & 0.007 & 1.00\end{array}$

$\begin{array}{llllll}1.51 & 0.021 & 0.014 & 0.97\end{array}$

$\begin{array}{llllll}0.72 & 0.041 & 0.057 & 0.90\end{array}$

$\begin{array}{lllll}0.58 & 0.018 & 0.031 & 0.90\end{array}$

$\begin{array}{lllll}0.67 & 0.016 & 0.024 & 0.27\end{array}$

$\begin{array}{lllll}1.15 & 0.031 & 0.027 & 0.83\end{array}$

$\begin{array}{llllll}0.95 & 0.039 & 0.041 & 0.63\end{array}$

$\begin{array}{lllll}0.30 & 0.014 & 0.046 & 0.83\end{array}$

$\begin{array}{lllll}0.73 & 0.027 & 0.037 & 0.73\end{array}$

$\begin{array}{llllll}0.76 & 0.019 & 0.025 & 0.63\end{array}$

$\begin{array}{lllll}0.95 & 0.030 & 0.032 & 0.63\end{array}$

$\begin{array}{lllll}0.65 & 0.042 & 0.065 & 0.67\end{array}$

$\begin{array}{lllll}0.61 & 0.022 & 0.036 & 0.00\end{array}$

$\begin{array}{lllll}0.85 & 0.022 & 0.026 & 0.00\end{array}$

$\begin{array}{lllll}0.85 & 0.020 & 0.024 & 0.17\end{array}$

$\begin{array}{lllll}0.68 & 0.026 & 0.038 & 0.10\end{array}$

$\begin{array}{lllll}0.72 & 0.022 & 0.030 & 0.13\end{array}$ 

4. TITLE AND SUBTITLE

Visual Assessment of Holograms

\section{5. $A \cup T H O R(S)$}

Belinda L. Collins

6. PERFORMING ORGANIZATION (If joint or other than NBS, see instructions)

NATIONAL BUREAU OF STANDARDS

DEPARTMENT OF COMMERCE

WASHINGTON, D.C. 20234

\section{SPONSORING ORGANIZATION NAME AND COMPLETE ADORESS (Street, City. State, ZIF)}

Bureau of Engraving and Printing

Department of the Treasury

Washington, D.C. 20228

\section{SUPPLEMENTARY NOTES}

Document describes a computer program; SF-185, FIPS Software Summary, is attached.

11. ABSTRACT (A 200-word or less factual summary of most significant information. If document includes a significant bibliography or literature survey, mention it here)

At the request of the Bureau of Engraving and Printing, NBS performed an assessment of the effectiveness of holograms intended for use as security devices on banknotes. Five holograms containing different portraits and counters were hotstamped on banknote currency of five different denominations. Each of the sixty-six banknotes, including 6 counterfeited holograms were then subjected to one of six wear testspristine, chemical soak, laundering, one crumple, two crumple, and four crumple. Thirty observers then participated in a visual performance experiment in which they detected the image, counter, and seal in each hologram, matched the image and counter to the portrait and counter on the note, rated the quality of each hologram, and indicated if it were genuine or counterfeit. The results indicated that wear adversely affected the performance of the holograms, with all wear conditions except chemical soak resulting in significantly poorer performance than the pristine condition, well below the criterion of 80 percent accuracy. Correlations with a physical measure of hologram quality, diffraction efficiency, were strongest for the rated quality measures, and were above 0.80 for image data. The data indicate strongly that the holograms studied could not pass standard wear tests that conventional banknote currency regularly dees.

12. KEY WOROS (Six to twelve entries; alphabetical order: capitalize only proper names: and seporote key words by semicolons) Banknotes; counterfeit; currency; detection; hologram; identification; optically variable devices; wear

\section{AVAILABILITY} 20402.

14. NO. OF PRINTED PAGES 




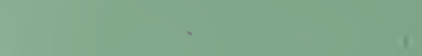

